\title{
Glossa
}

a journal of general linguistics

\section{The syntax and semantics of Japanese internally- and doubly-headed relatives}

\section{RESEARCH}

\section{CHRISTOPHER TANCREDI}

KOJI HOSHI

\section{ALEXANDER GROSU}

*Author affiliations can be found in the back matter of this article

\begin{abstract}
This paper proposes novel syntactic and semantic analyses of Japanese IHRCS and of a variety of DHRCs labelled 'integrated.' The analyses differ non-trivially from all earlier analyses known to us, both in orientation and in technical implementation, and their principal raison d'être is to capture, with minimal appeal to stipulation, the ways in which these two constructions differ from each other, from other relative constructions of Japanese, and from discourses with anaphoric dependencies. Our analysis of IHRCs builds on that of Landman (2016), and our analysis of integrated DHRCS is critically compared and contrasted with that of Erlewine \& Gould (2016), who aimed at a maximal analytical unification of Japanese EHRCS, IHRCS and DHRCS, failing to note some of their distinguishing properties and sometimes relying on incorrect empirical assumptions.
\end{abstract}

CORRESPONDING AUTHOR:

\section{Alexander Grosu}

Tel Aviv University, IL grosua@tauex.tau.ac.il

\section{KEYWORDS:}

internally headed relatives; doubly headed relatives; event(ualitie)s; Champollion event semantics; island constraints; Kuroda's Relevancy Condition

TO CITE THIS ARTICLE: Tancredi, Christopher, Koji Hoshi and Alexander Grosu. 2021. The syntax and semantics of Japanese internally- and doubly-headed relatives. Glossa: a journal of general linguistics 6(1): 93. 1-31. DOI: https://doi. org/10.16995/glossa.5887 


\section{Introduction}

Japanese exhibits three principal types of relative clause constructions: externally-headed relative clauses (EHRCs), internally-headed relative clauses (IHRCs), and doubly-headed relative clauses (DHRCs). EHRCs have either restrictive or appositive semantics and can be definite or indefinite. IHRCs cannot be appositive, and are necessarily definite. DHRCs are also necessarily definite, and can be either appositive or 'integrated' (in the sense of Grosu \& Hoshi 2019). A subordinate clause is integrated into its matrix if the two clauses may be fully contained within (the linguistic output of) a single illocutionary act. Appositive relatives and parentheticals have illocutionary force independently of their matrix, and thus form separate, non-integrated illocutionary units. The class of integrated subordinate clauses includes restrictive relatives and some DHRCs as proper sub-classes. To demonstrate (non-) integration, we will appeal to logical operators capable of defining illocutionary acts of denial and interrogation. Illustrations of EHRCs, IHRCs and DHRCs are provided in (1a-e). ${ }^{1}$ (1a,c,d) are taken from Erlewine \& Gould (2016). Here and elsewhere we put IHs in bold and EHs in normal text.

a. Junya-wa [[Ayaka-ga [e] mui-ta] ringo]-o tabe-ta. restrictive EHRC Junya-TOP Ayaka-NOM gap peel-PAST apple-ACC eat-PAST

'Junya ate some/the apple(s) that Ayaka peeled.'

b. Junya-wa [[Ayaka-ga $[e]$ mui-ta] ano ringo]-o

Junya-TOP Ayaka-NOM gap peel-PAST that apple-ACC

kat-ta.

appositive EHRC

buy-PAST

'Junya bought that apple/those apples, which Ayaka peeled.'

c. Junya-wa [[Ayaka-ga ringo-o mui-ta]-no]-o tabe-ta.

Junya-TOP Ayaka-NOM apple-ACC peel-PAST-NL-ACC eat-PAST

'Ayaka peeled some apple(s) $)_{\mathrm{i}}$ and Junya ate $\mathrm{it}_{\mathrm{i}} /$ them $_{\mathrm{i}}$ '.

d. Junya-wa [[Ayaka-ga ringo-o mui-ta] sono ringo]-o

Junya-TOP Ayaka-NOM apple-ACC peel-PAST that apple-ACC

tabe-ta.

eat-PAST

integrated

DHRC

'Ayaka peeled some apple(s) and Junya ate that/those apple(s) $)_{\mathrm{i}}$ '

d'. Context: Yoko put 18 of the 20 cookies in the fridge.

Ayaka-ga kukkii-o 20-mai tsukut-ta.

Ayaka-NOM cookies-ACC 20-CL make-PAST

Junya-wa [[Yoko-ga hotondo-no kukkii-o reezooko-ni ireteoi-ta]

Junya-TOP Yoko-NOM most-GEN cookie-ACC fridge-in put-PAST

sono kukkii]-o zenbu tabe-ta.

those cookies-ACC all eat-PAST

'Ayaka made 20 cookies. Yoko put most cookies in the fridge and Junya ate all the cookies [ = the 18 cookies in the fridge].'

e. Context: Yoko is thinking of putting 18 of the 20 cookies in the fridge.
Ayaka-ga kukkii-o
20-mai tsukut-ta.
appositive DHRC

Ayaka-NOM cookies-ACC 20-CL make-PAST

Junya-wa [[Yoko-ga kore-kara hotondo-no kukkii-o reezooko-ni

Junya-TOP Yoko-NOM this-after most-GEN cookies-ACC fridge-in

ire-yoo-to omottei-ru] ano/sono/kono kukkii]-o zenbu tabe-ru

put-will-COMP think-PRES those/those/these cookies-ACC all eat-PRES

tsumori da.

intention $\mathrm{COP}$

'Ayaka made 20 cookies. Junya intends to eat all those/these cookies [ $=20$ cookies made by Ayaka], most of which Yoko is thinking of putting in the fridge after this.' 
In this study, we will focus on the syntax and semantics of IHRCs and integrated DHRCs, our primary goal being to capture, with minimal appeal to stipulation, the ways in which these two types of constructions differ from each other and from the other types of relative constructions found in Japanese. To this end, we will offer analyses that differ non-trivially from all the earlier analyses of these constructions known to us. We assume the islandinsensitivity of EHRCs (see, e.g., Kuno 1973) is captured by the absence of movement relating the internal gap to the external head $(\mathrm{EH})$, but will otherwise refrain from analyzing EHRCs in detail. We implement our primary goal by proposing syntactic and semantic analyses of IHRCs and DHRCs that differ significantly from each other, as well as from the analyses we tacitly assume for EHRCs. In this respect, our approach differs strikingly from that of scholars who seek a maximally unified analysis of the three types of Japanese relative constructions, the most prominent example known to us being Erlewine \& Gould (2016), who proposed to derive all three types from a single underlying proto-structure. In focusing on the differences between the constructions we do not deny the existence of shared features, such as the fact that all three types have integrated varieties, and that two of them, EHRCs and DHRCs, share the property of island-insensitivity. However, we do not take such shared properties to suggest derivation from a shared source. ${ }^{2}$ After all, complement clauses and some adverbial clauses also share properties like integration, and yet we do not think anyone would want to derive all integrated subordinate clauses from a single source.

We aim to make this paper self-contained, but given the considerable literature on the topic and the length limits imposed by Glossa, we will be sparing in our summary of earlier proposals and controversies. The reader will benefit from familiarity with background studies, especially Grosu \& Hoshi (2016: §2), where it is shown in detail that IHRCs can be string-wise homophonous with at least three types of constructions that have quite distinct properties, and in which the item no plays a very different role. Failure to recognize homophony may lead to the misattribution of properties to IHRCs. ${ }^{3}$

Our analysis of IHRCs and DHRCs focuses exclusively on Japanese. We expect it might have wider applicability to comparable constructions in other languages and/or to other areas of Japanese grammar, though the only thing we can assert with any confidence is that, according to much earlier literature, Korean possesses IHRCs with essentially the properties of their Japanese counterparts, and so our analysis should be applicable to them. We have not closely examined DHRCs in other languages, but the information we have about IHRCs in other languages points to their all differing to varying degrees from the IHRCs of Japanese and Korean (see, e.g., Grosu 2012). We thus assume that at least certain aspects of our analysis will not generalize to them.

The remainder of the paper is organized as follows: In section 2, we list and illustrate a number of properties that determine distinct partitions of the class of constructions in (1a-e). In section 3 , we motivate and present our analyses of IHRCs and integrated DHRCs. Section 4 is a summary of results.

\section{The properties that partition the class of constructions in (1)}

\subsection{Integration}

EHRCs, IHRCs and integrated DHRCs are integrated, while appositive EHRCs and appositive DHRCs are not. We illustrate this state of affairs in (2)-(6), using interrogation and negation as operators whose scope cannot span two distinct illocutionary units. (2)-(4) are taken from Grosu \& Hoshi (2019).

2 For completeness, we note that Cinque (2021) pursues the even more ambitious goal of deriving all relative constructions in all languages of the world from a unique proto-source. However, since this project is pursued almost entirely within syntax, semantics kept at an intuitive level, we refrain from comments.

3 We acknowledge that the analysis developed below combined with the assumed possibilities of ambiguity will not account for the acceptability judgments of all apparent IHRCs - other constraints will need to be appealed to as well. We leave consideration of such extra constraints for another occasion. 
a. Junya-wa [[ dare-ga $[e]$ mui-ta $]$ ringo $]-0$ tabe-ta no. Junya-TOP who-NOM gap peel-PAST apple-ACC eat-PAST Q 'Who is such that Junya ate the apple(s) that (s)he peeled?'

b. Junya-wa [[Ayaka-ga [e] mui-ta] ringo]-o tabe-ta

restrictive

Junya-TOP Ayaka-NOM gap peel-PAST apple-ACC eat-PAST

EHRC

wake-de-wa na-i.

reason-COP-TOP NEG-PRES

'It is not true that Junya ate the apple(s) that Ayaka peeled.'

(NEG can target Ayaka. Possible continuation: he ate the apple(s) that Yoko peeled).

a. *Junya-wa [[ dare-ga [e] mui-ta] ano ringo]-o tabe-ta no. appositive Junya-TOP who-NOM gap peel-PAST that apple-ACC eat-PAST Q EHRC '*Who is such that Junya ate that apple/those apples, which (s)he peeled?'

b. Junya-wa [[Ayaka-ga [e] mui-ta] ano ringo]-o tabe-ta appositive Junya-TOP Ayaka-NOM gap peel-PAST that apple-ACC eat-PAST $\quad$ EHRC wake-de-wa na-i.

reason-COP-TOP NEG-PRES

'It is not true that Junya ate those apple(s), which Ayaka peeled.'

(NEG can only target the matrix; association with Ayaka in the $R C$ is excluded)

$\begin{array}{lll}\text { a. Junya-wa [ }[\text { dare-ga } & \text { ringo-o mui-ta }]-n o]-o & \text { tabe-ta no. } \\ \text { Junya-TOP who-NOM apple-ACC } & \text { peel-PAST-NL-ACC eat-PAST } \mathrm{Q}\end{array}$

IHRC 'Who is such that (s)he peeled an apple/apples and Junya ate them?'

b. Junya-wa [[Ayaka-ga ringo-o mui-ta]-no]-o tabe-ta IHRC Junya-TOP Ayaka-NOM apple-ACC peel-PAST-NL-ACC eat-PAST wake-de-wa na-i. reason-COP-TOP NEG-PRES 'It is not true that Ayaka peeled an apple/apples and Junya ate it/them.' (NEG can target Ayaka. Possible continuation: Yoko peeled an apple and Junya ate it.)

a. Junya-wa [[ dare-ga ringo-o mui-ta] sono ringo]-o tabe-ta Junya-TOP who-NOM apple-ACC peel-PAST that apple-ACC eat-PAST no

'Who is such that (s)he peeled an apple/apples and Junya ate it/them?'

b. Junya-wa [[ Ayaka-ga ringo-o mui-ta] sono ringo]-o tabe-ta integrated Junya-TOP Ayaka-NOM apple-ACC peel-PAST that apple-ACC eat-PAST DHRC wake-de-wa na-i.

reason-COP-TOP NEG-PRES

'It is not true that Ayaka peeled an apple/apples and Junya ate that apple/ those apples.'

(NEG can target Ayaka. Possible continuation: Yoko peeled an apple and Junya ate that apple.)

(6)

a. Context: Someone is thinking of putting 18 of the 20 cookies in the fridge.

Ayaka-ga kukkii-o 20-mai tsukut-ta.

appositive DHRC

Ayaka-NOM cookies-ACC 20-CL make-PAST

*Junya-wa [[ dare-ga kore-kara hotondo-no kukkii-o reezooko-ni

Junya-TOP who-NOM this-after most-GEN cookies-ACC fridge-in

ire-yoo-to omottei-ru] ano/kono ${ }^{4}$ kukkii]-o zenbu tabe-ru tsumori

put-will-COMP think-PRES those/these cookies-ACC all eat-PRES intention

na no

COP Q

'Ayaka made 20 cookies. Who is such that (s)he is thinking of putting most of the cookies [ $=18$ cookies] in the fridge after this and Junya intends to eat all of them $[=20$ cookies $]$ ?' 
b. Context: Someone other than Ayaka is thinking of putting 18 of the 20 cookies in the fridge.

Ayaka-ga kukkii-o 20-mai tsukut-ta.

Ayaka-NOM cookies-ACC 20-CL make-PAST

Junya-wa [[Ayaka-ga kore-kara hotondo-no kukkii-o reezooko-ni

Junya-TOP Ayaka-NOM this-after most-GEN cookies-ACC fridge-in

ire-yoo-to omottei-ru] ano/kono kukkii-o] zenbu tabe-ru

put-will-COMP think-PRES those/these cookies-ACC all eat-PRES

tsumori na wake-de-wa na-i. ${ }^{5}$

appositive DHRC

intention COP reason-COP-TOP NEG-PRES

'Ayaka made 20 cookies. Impossible intended construal: It is not true that

Ayaka is thinking of putting most of the cookies $[=18$ cookies $]$ in the fridge

after this and that Junya intends to eat all of them $[=20$ cookies $]$. (It's

Yoko who is thinking of putting most of the cookies in the fridge.)' 'Available

construal: It is not true that Junya intends to eat all of those/these cookies

[ $=20$ cookies $]$, most of which Ayaka is thinking of putting in the fridge after

this.'

(NEG can only target the matrix; association with Ayaka in the $R C$ is excluded)

The CP of IHRCs disallows an appositive construal, and so is necessarily integrated. The CP of DHRCs can be either integrated or appositive. We focus in this paper on only integrated DHRCs and make no attempt to give a formal analysis of appositive DHRCs. For the remainder of this paper, we will use the term DHRC, without modification, to refer exclusively to integrated DHRCs.

\subsection{Necessary definiteness}

The property of necessary definiteness sets apart IHRCs and DHRCs, which possess it, from EHRCs, which may be either definite or indefinite and which essentially allow the range of interpretations permitted by their English counterparts. The necessary definiteness of IHRCs and DHRCs, and the possibility of an indefinite construal for restrictive EHRCs, are reflected in the fluent English translations of (1c-e) and (1a) respectively; in (1b), the external head (EH) is necessarily definite because of the demonstrative ano (= that), but an illustration of the indefinite option is provided by the observation that in (1a), a slight hiatus after the relative clause makes available a non-restrictive interpretation translatable as "Junya ate an apple/ some apples, which Ayaka had peeled."

The necessary definiteness of IHRCs has given rise to analyses of the relative CP as denoting a proposition in which the internal head (IH) serves as antecedent to an (overt or null) E-type definite anaphor in the matrix (Hoshi 1995; Shimoyama 1999; 2001; Kim 2007). This approach is reflected in the format of the fluent English translation of (1c), which was adopted in Shimoyama (1999; 2001), and constitutes the best approximation known to us for capturing the truth conditions of IHRCs. This format is also suitable for approximating the truth conditions of DHRCs, and we adopt it for both constructions in this paper without intending to imply that the interpretations of IHRCs and DHRCs are identical.

Analyzing IHRCs and DHRCs as analogous to discourses with two juxtaposed or coordinated sentences related by a discourse anaphoric dependency can in many cases successfully capture their truth conditions (and may even reflect their diachronic evolution, a possibility suggested in Kuroda 1999a with respect to IHRCs). However, such an approach does not capture the ways in which these two constructions differ from discourses with anaphora. In particular, both constructions are integrated in a way in which discourses cannot be. Additionally, IHRCs differ from discourses in exhibiting the properties examined in Sections 2.3-2.5. In response to this state of affairs, Grosu (2010), Grosu \& Landman (2012) and Landman (2016) proposed analyses of IHRCs that do not rely on discourse anaphora. Kitagawa's (2019) defense of the discourse anaphoric approach was critiqued and rejected by Grosu \& Hoshi (2019) on grounds that we agree with, and will not reproduce here. In this study, we will develop an analysis of IHRCs that 
rejects a discourse anaphoric approach, but which also aims to account for the distinguishing properties of IHRCs and DHRCs with as few stipulations as possible. Our analysis of DHRCs may be viewed as a 'grammatization' of the discourse anaphoric approach, though one in which the anaphora is obligatorily mediated by an event.

\subsection{Sensitivity to syntactic islands}

A property that sets IHRCs apart from the other constructions in (1) (as well as from discourses with anaphora) is sensitivity to a number of syntactic islands, in particular, to Complex NPs, Adjunct Islands, Coordinate Structures, and Left Branches.

Sensitivity to the Complex NP Constraint was noted and illustrated in Watanabe (1992), and defended against challenges (e.g., Kitagawa 2005) in Grosu \& Hoshi (2016: §3). Sensitivity to the Adjunct Island Constraint was denied in Hoshi (1995) and Kuroda (1999a), but the argumentation in these works was refuted in Grosu \& Hoshi (2016: §3). Sensitivity to the Coordinate Structure Constraint has not, as far as we know, been noted in earlier literature. That a possessor cannot be an IH of an IHRC was observed in Shimoyama (2001), which we analyze here as sensitivity to the Left Branch Condition. We illustrate the sensitivity of IHRCs to these four constraints in (7). (7a,b) show that the IH may be internal to a complement clause, but not to an EHRC embedded within the IHRC. (7c) shows that the IH may not be internal to an adverbial clause. (7d) shows that a coordinate structure cannot have an IH contained in a single conjunct but can have IHs in all the conjuncts (i.e., IHs need to be present 'across the board'). Finally, (7e) illustrates that the IH cannot occur in a Left Branch. ${ }^{6}$ (7a,b) are from Watanabe (1992).

a. Mary-wa [[John ${ }_{\mathrm{i}}$-ga [jibun $_{\mathrm{i}}$-no gakusei-ga juuyouna kasetsu-o Mary-TOP John-NOM self-GEN student-NOM important hypothesis-ACC teian-shi-ta to] jimanshite-ita]-no]-no kekkan]-o shiteki-shi-ta. propose-do-PAST COMP boasted-had-NL-GEN defect-ACC point.out-do-PAST '[John had boasted [that his student proposed an important hypothesis]] and Mary pointed out a defect in it.'

b. *Mary-wa [[[John-ga [[atarashii kasetsu-o teianshi-ta] Mary-TOP John-NOM new hypothesis-ACC propose-PAST gakusei]-o homete-ita]-no]-no kekkan]-o shiteki-shi-ta. student-ACC praise-had-NL-GEN defect-ACC point.out-do-PAST 'John praised [the student [who proposed a new hypothesis]] and Mary pointed out a defect in it.'

c. ?*Mary-wa [[[ John $_{i}$-ga [jibun ${ }_{i}$-no gakusei-ga atarashii kasetsu-o Mary-TOP John-NOM self-GEN student-NOM new hypothesis-ACC teianshi-ta node] kanki-no koe-o age-ta]-no]-no

propose-PAST because joy-GEN voice-ACC raise-PAST-NL-GEN

akirakana kekkan]-o suguni shiteki-shi-ta. obvious defect-ACC promptly point.out-do-PAST 'John shouted with joy [because his student proposed a new hypothesis], and Mary promptly pointed out an obvious defect in it.' 
d. Junya-wa [[John-ga san-ko-no nashi-o kat-te Mary-ga

Junya-TOP John-NOM three-CL-GEN pear-ACC buy-and Mary-NOM

ni-ko-no ringo-o kat-ta]-no]-o tabe-ta.

two-CL-GEN apple-ACC buy-PAST-NL-ACC eat-PAST

'John bought three pears and Mary bought two apples and Junya ate them

( = the 3 pears and 2 apples/*the three pears/*the two apples).'

e. \#[[Taro-ga jibun-no musume-no hito-ri-no sushi-o kyaku-ni

Taro-NOM self-GEN daughter-GEN one-CL-GEN sushi-ACC guest-DAT dashi-ta]-no]-o kyaku-ga suguni home-ta.

serve-PAST-NL-ACC guest-NOM immediately praise-PAST

'(Intended) Taro served to the guest the sushi of one of his daughters] and the guest immediately praised her.'

In contrast to IHRCs, DHRCs are insensitive to the four constraints noted above, as illustrated in (8). In this respect, DHRCs resemble discourses and EHRCs (illustration omitted). (8a,b) are from Grosu \& Hoshi (2018).
a. Mary-wa
[[]John-ga
$\left[\left[[e]_{\mathrm{i}}\right.\right.$ atarashii kasetsu-o
teianshi-ta]
Mary-TOP John-NOM gap new hypothesis-ACC propose-PAST
gakusei $_{\mathrm{i}}$ ]-o homete-ita] sono atarashii kasetsu]-no kekkan]-o
student-ACC praise-had that new hypothesis-GEN defect-ACC
shiteki-shi-ta.
point.out-do-PAST
'John praised the student who proposed a new hypothesis and Mary pointed out a defect in that new hypothesis.'

b. Mary-wa [[[ $\mathrm{John}_{\mathrm{i}}$-ga [jibun ${ }_{\mathrm{i}}$-no gakusei-ga atarashii kasetsu-o

Mary-TOP John -NOM $^{-N e l f}$-GEN student-NOM new hypothesis-ACC

teianshi-ta] node kanki-no koe-o age-ta] sono atarashii

propose-PAST because joy-GEN voice-ACC raise-PAST that new

kasetsu]-no akirakana kekkan]-o suguni shiteki-shi-ta.

hypothesis-GEN obvious defect-ACC promptly point.out-do-PAST

'John shouted with joy because his student had proposed a new hypothesis and Mary pointed out an obvious defect in that new hypothesis.'

c. Junya-wa [[John-ga san-ko-no nashi-o kat-te Mary-ga

Junya-TOP John-NOM three-CL-GEN pear-ACC buy-and Mary-NOM

ni-ko-no ringo-o kat-ta] sono ringo/kudamono]-o tabe-ta.

two-CL-GEN apple-ACC buy-PAST that apple/fruit-ACC eat-PAST

'John bought three pears and Mary bought two apples and Junya ate those

apples/ that fruit ( = the 3 pears and the 2 apples).'

d. [[Taro-ga jibun-no musume-no hito-ri-no sushi-o kyaku-ni

Taro-NOM self-GEN daughter-GEN one-CL-GEN sushi-ACC guest-DAT dashi-ta] sono musume]-o kyaku-ga suguni home-ta.

serve-PAST that daughter-ACC guest-NOM immediately praise-PAST

'Taro served to the guest the sushi of one of his daughters and the guest

immediately praised that daughter (in question).'

\subsection{Kuroda's (1975/76) Relevancy Condition}

An important property that sets IHRCs apart from the other relative constructions and from discourses, and from the IHRCs of all languages other than Japanese and Korean about which we have information, is the Kuroda Relevancy Condition (KRC). This condition is notoriously difficult to define precisely. We confine ourselves to the following informal characterization based on Landman (2016): ${ }^{7}$

\footnotetext{
7 For the purposes of this paper, the precise formulation of the KRC is not as important as is the observation that KRC effects exist. In that light, the examples that we identify as differing in whether they satisfy the KRC are better seen as placing constraints on a proper characterization of the KRC rather than as results derivable from the formulation of the KRC given in (9).
} 
The eventualities denoted by the relative clause and its matrix need to be

Reference to context is meant to highlight the fact that pragmatics plays an important role in (dis)allowing satisfaction of the KRC, and the term natural is vague in a way that allows crossidiolectal variation, depending on how much pragmatic bridging one is willing to appeal to. We illustrate the sensitivity of IHRCs to the KRC in (10), where the (a) subcase satisfies this condition and the (b) subcase does not. We conjecture that the infelicity of (10b) is due to the fact that the kind of pragmatic bridging needed to achieve a 'natural' single eventuality is too far-fetched to be realistic (one could assume, e.g., that a fish had been thrown out of the kitchen window yesterday by a cook, that the cat exited the kitchen in order to get it, and that the fish was so large that the cat had not finished eating it one day later). The insensitivity of discourses and DHRCs to the KRC is illustrated in (11) and (12), which are minimally distinct counterparts of (10). (10a,b) are adapted from Shimoyama (2001), and (12b) is from Grosu \& Hoshi (2018).

a. [[Daidokoro-no mado-kara shiroi neko-ga haitteki-ta]-no]-ga kitchen-GEN window-from white cat-NOM come.in-PAST-NL-NOM ima sakana-o totte nige-ta. now fish-ACC steal run.away-PAST

'A white cat came in from the kitchen window and it now stole a fish and ran away.'

b. ?*[[Daidokoro-no mado-kara shiroi neko-ga kinoo deteit-ta]-no]-ga

kitchen-GEN window-from white cat-NOM yesterday go.out-PAST-NL-NOM ima sakana-o tabete-i-ru. now fish-ACC eat-Prog-PRES

'A white cat went out of the kitchen window yesterday and it is (now) eating a fish.'

(11) a. Daidokoro-no mado-kara shiroi neko-ga haitteki-ta ga, ima sakana-o kitchen-GEN window-from white cat-NOM come.in-PAST and now fish-ACC totte nige-ta. steal run.away-PAST

'A white cat came in from the kitchen window and it now stole a fish and ran away.'

b. Daidokoro-no mado-kara shiroi neko-ga kinoo deteit-ta ga, ima kitchen-GEN window-from white cat-NOM yesterday go.out-PAST and now sakana-o tabete-i-ru.

fish-ACC eat-Prog-PRES

'A white cat went out of the kitchen window yesterday and it is now eating a fish.'

a. [[Daidokoro-no mado-kara shiroi neko-ga haitteki-ta] sono shiroi kitchen-GEN window-from white cat-NOM come.in-PAST that white neko]-ga ima sakana-o totte nige-ta. cat-NOM now fish-ACC steal run.away-PAST

'A white cat came in from the kitchen window and that white cat now stole a fish and ran away.'

b. [[Daidokoro-no mado-kara shiroi neko-ga kinoo deteit-ta] sono kitchen-GEN window-from white cat-NOM yesterday go.out-PAST that shiroi neko]-ga ima sakana-o tabete-i-ru. white cat-NOM now fish-ACC eat-Prog-PRES 'A white cat went out of the kitchen window yesterday, and that white cat is now eating a fish.' 
We do not feel we can significantly improve on earlier attempts to define the content of the $\mathrm{KRC},{ }^{8}$ but we do feel we can improve on the characterization of the domain over which it operates. The past literature has discussed the KRC mostly in relation to data like (10), where the IHRC consists of a simplex clause and serves as argument of the matrix verb, and has paid little attention to more complex data, e.g., to data like (7a), where one needs to decide whether the 'lower' relevant eventuality is the one described by the entire relative clause or by the clause that immediately embeds the IH. We will address this issue in relation to a variety of situations in Section 3, where we will present evidence in support of the view that the KRC concerns only 'hierarchically adjacent' eventualities.

\subsection{The (in)felicity of referential IHs}

One final property that distinguishes IHRCs from DHRCs (and discourse anaphora) is that the IH of an IHRC cannot be a proper name or demonstrative expression, as illustrated in (13), adapted from Grosu \& Hoshi (2016), while both are unproblematic as IHs of DHRCs, as illustrated in (14). We omit illustration of the exceedingly well-known fact that discourse anaphora allows definite referential antecedents.

?*Ken-wa [[[Naomi-ga ofisu-ni \{Lucky-o/ sono haiiro-no neko-o
Ken-TOP Naomi-NOM office-DAT Lucky-ACC/ that grey-GEN cat-ACC
tsureteki-ta]-no]-no ke]-o kat-ta.
bring-PAST-NL-GEN hair-ACC cut-PAST
'Naomi brought $\{$ Lucky / that gray cat $\}$ to the office and Ken cut her hair.'

Ken-wa [[[Naomi-ga ofisu-ni \{Lucky-o/ kono haiiro-no neko-o $\}$
Ken-TOP Naomi-NOM office-DAT Lucky-ACC this grey-GEN cat-ACC
tsureteki-ta] sono $\{$ Lucky/ kono haiiro-no neko\}]-no ke]-o kat-ta.
bring-PAST that Lucky this grey-GEN cat-GEN hair-ACC cut-PAST
'Naomi brought \{Lucky, this grey cat $\}$ to the office and Ken cut that $\{$ Lucky's/
this grey cat's\} hair.'

\section{Analysis}

Past attempts to analyze relative clause constructions have taken EHRCs, IHRCs and DHRCs to all have external heads (EHs), with the EH of an IHRC being covert (Hoshi 1995; Shimoyama 1999; 2001; Grosu 2010; Grosu \& Landman 2012; Grosu \& Hoshi 2016; 2019; Erlewine \& Gould 2016; Kitagawa 2019). These analyses largely give a syntactic and semantic account of the referential properties of the three constructions but leave any differences in their restrictions to the pragmatics. While it is possible to stipulate the relevant restrictions - IHRCs are subject to movement constraints, have to satisfy Kuroda's (1975/76) Relevancy Condition (KRC), the IH of an IHRC cannot be identifying (alternatively put, referential), and IHRCs and DHRCs have to be definite - the fact that these restrictions do not apply uniformly to all three constructions

8 Kim (2007) proposes that the KRC requires that the time of the relative precede the time of the matrix, a view also put forward by reviewer A. Grosu (2010) argues, on the basis of his example (33), that it suffices for an eventuality implied by the relative to temporally precede the time of the matrix. Landman (2016) goes one step further and offers data in which both types of temporal orders are acceptable (see his (33)). We construct an additional pair of examples in (i)-(ii).

(i) Yoko-wa $\left[\right.$ [[Taro-ga asa pro $_{i}$ gesuto-o shookai-si-ta]-no]-o 3-nin] yoru-ni dinaa Yoko-TOP Taro-NOM morning guest-ACC introduce-do-PAST-NL-ACC 3-CL evening-indinner paatii-ni shootai-si-ta.

party-to invite-do-PAsT

'Taro introduced three guests to Yoko in the morning and she invited them to a dinner party in the evening.'

(ii) Taro-wa [[[Yoko ga $_{\mathrm{i}}$ yoru-ni dinaa paatii-ni gesuto-o shootai-si-ta]-no]-o 3-nin $]$ asa pro $_{i}$ Taro-TOP Yoko-NOM evening-in dinner party-to guest-ACC invite-do-PAST-NL-ACC 3-CL morning \{? shookai-si-ta/ shookai-shite-i-ta\}. introduce-do-PAST/ introduce-do-be-PAST

'Yoko invited three guests to a dinner party in the evening and Taro ?(had already) introduced them to her in the morning.'

Our consultants report that the version of (ii) marked with '?' is slightly degraded relative to (i), but the alternative version is fine. We surmise that the temporal order relative $<$ matrix might well facilitate satisfaction of the KRC, but is not an absolute requirement, and can be overcome by manipulating the matrix, as in (ii). 
has not been given a principled explanation to date. One important partial exception is the analysis of IHRCs in Landman (2016), which accounts for the movement constraints, obligatory definiteness, and KRC effects in IHRCs in a way that is at least potentially inapplicable to DHRCs and EHRCs.

Below we give separate analyses of IHRCs and DHRCs that account for the differences between these constructions outlined in Section 2. Our analysis of IHRCs in Sections 3.1.2 (syntax) and 3.1.3 (semantics) constitutes a modification of Landman (2016), which is reviewed in Section 3.1.1. Our proposal preserves Landman's explanations for movement effects and definiteness while reducing construction-specific stipulations, improving on empirical predictions for KRC effects, and accounting for the restriction against identifying heads. These results are spelled out in section 3.1.4.

Our analysis of DHRCs is novel, departing radically from the only other formal analysis of DHRCs we know of, that of Erlewine \& Gould (2016, henceforth EG). EG propose to unify DHRCs with EHRCs and IHRCs by deriving them all from a single source. We present a critique of EG's analysis of DHRCs in Section 3.2.2 ${ }^{9}$ that also serves to outline additional properties of DHRCs that any analysis must explain. We then give our proposed analysis of DHRCs in Sections 3.2.3 (syntax) and 3.2.4 (semantics). In Section 3.2.5 we show how the proposed analysis derives the properties of DHRCs from the semantics of the demonstrative element so(that) that occurs obligatorily in their EH and acts semantically as the DHRC head.

\subsection{IHRCS}

\subsubsection{Landman (2016)}

According to Landman, the internal structure of an IHRC is as follows:

$$
\left.\left[\mathrm{CP}_{\mathrm{CP}} \mathrm{Op}_{\mathrm{n}}\left[\mathrm{C}_{\mathrm{C}}\left[\ldots \mathrm{XP}_{1}\left[\mathrm{XP}_{2} \ldots \mathrm{IH} \ldots\right]\left[\mathrm{PP}_{\mathrm{n}} \mathrm{P}\right]\right] \ldots\right]\right]\right]
$$

The trace $t_{n}$ is interpreted as an individual variable $x_{n}$, abstracted over ultimately by $O p_{n}$. The phonetically null $P$ is stipulated to pick out a thematic role $\pi$ among the roles associated with the event predicated by the head $X$ of $X P$ and to identify the bearer of $\pi$ with $x_{n}$. If we take $X P_{2}$ to denote an event predicate $E$, the interpretation of $X P_{1}$ is:

$$
\text { גe. } E(e) \& \pi(e)=x_{n}
$$

Existential closure of the event variable occurs below the predicate abstraction induced by $O p_{n}$. In the case in which the IHRC contains only a single clause with no embedding, the interpretation for the $\mathrm{CP}$ as a whole can be simplified as follows, ignoring tense and aspect:

$$
\lambda \mathrm{x}_{\mathrm{n}} \cdot \exists \mathrm{e}\left[\mathrm{E}(\mathrm{e}) \& \pi(\mathrm{e})=\mathrm{x}_{\mathrm{n}}\right]
$$

Since $\pi$ is selected from among the roles assigned within $E, \pi(e)$ ends up doubly restricted in (17). This is best seen by looking at an example. Consider the IHRC Ayaka-ga kukkii-o tsukut-tano (= Ayaka made cookies). With the IH coming from the Th(eme) role associated with kukkii, the $\mathrm{CP}$ has the following (simplified) interpretation:

$$
\lambda \mathrm{x}_{\mathrm{n}} \cdot \exists \mathrm{e}\left[\mathrm{make}(\mathrm{e}) \& \operatorname{Ag}(\mathrm{e})=\text { Ayaka } \& \operatorname{cookies}(\mathrm{Th}(\mathrm{e})) \& \operatorname{Th}(\mathrm{e})=\mathrm{x}_{\mathrm{n}}\right]
$$

The CP interpretation derived in this manner is a property denotation. Landman assumes "that the implicit definiteness operation $\sigma$ [where $\sigma(\mathrm{P})$ is the sum of the elements in $\mathrm{P}$ on the presupposition that that sum itself is in P] brings the relative in argument position from a predicative meaning to a definite interpretation at the type of individuals." Concretely, this operation generates (19) as the final interpretation of the IHRC.

$$
\sigma\left(\lambda x_{n} \cdot \exists e\left[\text { make(e) \& Ag(e)=Ayaka \& cookies(Th(e)) \& Th(e)= } x_{n}\right]\right)
$$

This denotes the maximal plural individual that is cookies that Ayaka made.

Landman also incorporates a formal analysis of K(uroda) R(elevency) effects into the semantics of IHRCs. Intuitively, KR effects indicate a restriction on the relation that can hold between

9 Critiques of EG's analysis of IHRCs can be found in Grosu \& Hoshi (2018) and Moulton \& Shimoyama (2018). We do not repeat those critiques here. 
the matrix event of which an IHRC is an argument on the one hand and the IHRC event on the other. Landman builds this restriction into the semantics of the empty postposition $\mathrm{P}$ used to select a thematic role for identifying the IH of the IHRC. He does so by employing a contextually supplied Kuroda Relevancy function $\mathbf{k}$, where for all e, e', $\mathbf{k}(\mathrm{e})=\mathrm{e}^{\prime}$ iff e, e' satisfy the KRC (= (9)). Incorporating this function into the semantics of $P$ results in the following schematic interpretations for $X P_{1}$ and $C P$ in (15), where $\mathrm{e}^{\prime}$ is a free variable:

$$
\begin{array}{ll}
\mathrm{XP}_{1}: & \lambda \mathrm{e} . \mathrm{E}(\mathrm{e}) \& \pi(\mathrm{e})=\mathrm{x}_{\mathrm{n}} \& \mathbf{k}(\mathrm{e})=\mathrm{e}^{\prime} \\
\mathrm{CP}: & \lambda \mathrm{x}_{\mathrm{n}} \cdot \exists \mathrm{e}\left[\mathrm{E}(\mathrm{e}) \& \pi(\mathrm{e})=\mathrm{x}_{\mathrm{n}} \& \mathbf{k}(\mathrm{e})=\mathrm{e}^{\prime}\right]
\end{array}
$$

After application of the definiteness operation $\sigma, \mathrm{e}^{\prime}$ is ultimately identified with the event variable of the matrix event predicate, establishing the desired connection between the IHRC event and the matrix event.

While Landman's analysis represents clear progress in analyzing IHRCs and accounting for their KR effects, the analysis faces two problems. First, it is central to Landman's analysis that free variables be allowed to take on contextual values, as seen in the fact that the free Kuroda Relevancy function variable $\mathbf{k}$ does so. Allowing the same possibility for the free event variable introduced in (20), however, causes problems. In particular, it leads to the incorrect prediction that KR-violating IHRCs can be salvaged by embedding them in a discourse with an antecedent that together with the IHRC satisfies the KRC. For example, (21) is predicted to be acceptable, contrary to observation.

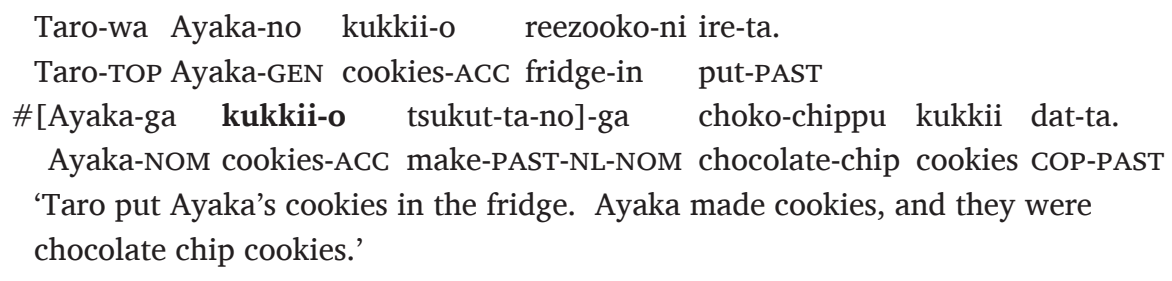

The second sentence of (21) is unacceptable on its own as an IHRC, presumably because the events $e$ of Ayaka's making cookies and $e^{\prime}$ of the cookies being chocolate chip cookies do not satisfy the KRC. ${ }^{10}$ The following sentence, however, is acceptable, indicating that the KRC is satisfied by $e$ and the event $e^{\prime \prime}$ of Taro's putting the cookies in the fridge.

$$
\begin{aligned}
& \text { Taro-wa [Ayaka-ga kukkii-o tsukut-ta-no]-o reezooko-ni ire-ta. } \\
& \text { Taro-TOP Ayaka-NOM cookies-ACC make-PAST-NL-ACC fridge-in put-PAST } \\
& \text { 'Ayaka made cookies, and Taro put them in the fridge.' }
\end{aligned}
$$

Since the first sentence of (21) is nothing more than an independent characterization of this $e^{\prime \prime}$, if $e^{\prime \prime}$ could be identified pragmatically as the value of $\mathbf{k}(\mathrm{e})$ within the IHRC in the second sentence of (21), the KRC would be satisfied and the example predicted to be acceptable. Somehow this result needs to be blocked, but Landman gives us no principled basis for doing so.

10 Reviewer A points out that (21) improves when embedded as in (i).

(i) ?Kinou Ayaka-ga kukkii-o tsukut-ta-no-ga chokochippu kukkii dat-ta-node,

Yesterday Ayaka-NOM cookies-ACC make-PAST-NL-NOM chocolate.chip cookie COP-PAST-because

choko-zuki-no Junya-wa yorokon-da.

chocolate-loving-GEN Junya-TOP be.pleased-PAST.

'Because Ayaka made cookies yesterday and they were chocolate chip cookies, Junya, a chocolate lover, was happy.'

We suggest that the perceived improvement derives from node 'because' helping to coerce an adverbial interpretation of the nominative-marked clause scoping over chokochippu kukkii dat-ta-node, choko-zuki-no Junya-wa yorokon-da, since under such an interpretation, but not under an IHRC interpretation, it is possible for Ayaka-ga kukkii-o tsukutta-no-ga to fall outside the scope of node. The resulting construal of the sentence is a perfectly reasonable one, expressible in English by As Ayaka made cookies yesterday, because they were chocolate chip cookies, Junya, a chocolate lover, was happy. Note that if this adverbial together with chokochippu kukkii dat-ta falls within the scope of node, a non-sensical interpretation results, which can be rendered in English by \#Because as Ayaka made cookies yesterday they were chocolate chip cookies, Junya, a chocolate lover, was happy, saying in effect that the existence of a causal relation between Ayaka's making cookies and their being chocolate chip cookies pleases a chocolate lover.

To be sure, a basically acceptable adverbial reading of Ayaka-ga kukkii-o tsukutta-no-ga can also be imposed on (21) by inserting a pause after this constituent (Kuroda (1999a: 72)), but this reading is otherwise distinctly less salient than in (i). 
The second problem with Landman's analysis is that even restricting the relevant events to sentence-internal events, it makes incorrect predictions about which events need to satisfy the KRC. Since the KR operator is introduced by the $P$ that locally fixes the IH as a thematic participant in the $X P_{2}$ sister of its $P P$ projection in (15), the analysis predicts that KR should be required to hold between the main $X P_{2}$ event and an IHRC-external event. For IHRCs with only a single clause this prediction is borne out. For IHRCs whose IH resides in an embedded clause, however, it is not. This can be seen by comparing the following examples.

$$
\begin{aligned}
& \text { a. Junya-wa [Ayaka-ga kesa kukkii-o tsukut-ta-no]-o } \\
& \text { Junya-TOP Ayaka-NOM this-morning cookies-ACC make-PAST-NL-ACC } \\
& \text { sudeni tabeteshimat-ta. } \\
& \text { already eat.up-PAST } \\
& \text { 'Ayaka made cookies this morning, but Junya already ate them up.' } \\
& \text { b. \#Junya-wa [Taro-ga [Ayaka-ga kesa kukkii-o } \\
& \text { Junya-TOP Taro-NOM Ayaka-NOM this-morning cookies-ACC } \\
& \text { tsukut-ta-to] (kore-kara) houkoku-su-ru-no]-o sudeni } \\
& \text { make-PAST-COMP(this-after) announce-do-PRES-NL-ACC already } \\
& \text { tabeteshimat-ta. } \\
& \text { eat.up-PAST } \\
& \text { 'Taro will announce (after this) that Ayaka made cookies this morning, but } \\
& \text { Junya already ate them up.' } \\
& \text { c. Junya-wa [[Taro-ga [Ayaka-ga kesa [e] tsukut-ta-to] } \\
& \text { Junya-TOP Taro-NOM Ayaka-NOM this-morning gap make-PAST-COMP } \\
& \text { (kore-kara) houkoku-su-ru] kukkii]-o sudeni tabeteshimat-ta. } \\
& \text { (this-after) announce-do-PRES cookies-ACC already eat.up-PAST } \\
& \text { 'Junya already ate up the cookies that Taro will announce (after this) that } \\
& \text { Ayaka made this morning.' }
\end{aligned}
$$

The acceptability of (23a) shows that the KRC is satisfied by the IHRC event of Ayaka making cookies and the matrix event of Junya eating them. In (23b), if the KRC were required to hold between the most embedded event and the matrix event, the example would be predicted to be acceptable since this results in the same two events having to satisfy the KRC as were seen to satisfy it in (23a). The fact that (23b) is not acceptable strongly suggests that the KRC relates the matrix event not to the event of the minimal IH-containing clause but to the event of the highest clause in the IHRC. The example in (23c) shows that the corresponding EHRC, which lacks any KRC requirement, is acceptable, further corroborating this suggestion.

The problem of identifying the events that the KRC constrains shows up not only with the IHRCinternal event but also with the IHRC-external event. Kuroda (1999a; b) identifies this latter event as the main event of the expression that selects the IHRC. While Landman's analysis allows this to be the relevant event, since it relies essentially on binding of a free event variable $e^{\prime}$, and since variable binding can occur over arbitrarily long distances, Landman's analysis predicts that it should be possible for an example to satisfy the KRC non-locally. In particular, an IHRC selected by a head $\mathrm{H}$ with respect to which the KRC is not satisfied is predicted to be salvageable if the entire [IHRC $\mathrm{H}$ ] construction is embedded under a higher predicate $\mathrm{H}^{*}$ when the KRC is satisfied by the IHRC and $\mathrm{H}^{*}$. This prediction as well is not borne out, as seen in the examples below.

a. \#[Ayaka-ga kukkii-o tsukut-ta-no]-ga choko-chippu kukkii-de aru. Ayaka-NOM cookies-ACC make-PAST-NL-NOM chocolate-chip cookies-COP Intended: 'Ayaka made cookies, and they are chocolate chip cookies.'

b. Junya-wa [Ayaka-ga kukkii-o tsukut-ta-no]-o tanoshin-da. Junya-TOP Ayaka-NOM cookies-ACC make-PAST-NL-ACC enjoy-PAST 'Ayaka made cookies, and Junya enjoyed them.' 
c. \#Junya-wa [[[Ayaka-ga kukkii-o tsukut-ta-no]-ga choko-chippu Junya-TOP Ayaka-NOM cookies-ACC make-PAST-NL-NOM chocolate-chip kukkii-de aru] oyatsu]-o tanoshin-da. cookies-COP snack-ACC enjoy-PAST Intended: 'Ayaka made cookies, and they are chocolate chip cookies; Junya enjoyed the snack.'

d. Junya-wa [[Ayaka-ga [e] tsukut-ta] kukkii]-ga choko-chippu Junya-TOP Ayaka-NOM gap make-PAST cookies-NOM chocolate-chip kukkii-de aru] oyatsu]-o tanoshin-da. ${ }^{11}$ cookies-COP snack-ACC enjoy-PAST 'The cookies Ayaka made are chocolate chip cookies; Junya enjoyed the snack.'

(24a) shows again that the eventualities of Ayaka making cookies and of the cookies being chocolate chip cookies do not satisfy the KRC. (24b) shows that the events of Ayaka making cookies and of Junya enjoying them do satisfy the KRC. If the KRC could be satisfied long distance, (24c) would be expected to be acceptable since it would essentially relate the same two events as (24b). That it is not acceptable where its EHRC counterpart in (24d) is acceptable strongly suggests that the problem with (24c) stems from its not satisfying the KRC.

\subsubsection{IHRC syntax}

We analyze IHRCs syntactically as bare CPs, lacking an EH. We introduce an IHRC-specific operator $O p$ that exploits the mechanisms of thematic role assignment to identify the $\mathrm{IH}$, replacing the ad hoc ChR operator from Grosu \& Landman (2012) and the equally ad hoc empty postposition P from Landman (2016). We follow Champollion (2015) in separating lexical predicates from thematic role assignment both in the syntax and in the semantics. ${ }^{12}$ We take thematic role assigners to be syntactic expressions that combine first with an argument of a syntactic predicate and then with the predicate itself. We accomplish IHidentification by adding a second occurrence of a particular thematic role assigner to a predicate. The internal syntactic argument of this thematic role assigner is an operator that raises eventually to SpecCP, where it takes three arguments: (i) (the predicate abstraction of) its $C^{\prime}$ sister, (ii) an IHRC-external thematic role assigner, and (iii) an IHRC-external event quantifier (typically a projection of the matrix V). This raising is assumed to give rise to island effects. The schematic internal structure of the CP of an IHRC is given below, where $\theta$ is a thematic role assigner that assigns a role of the head of $X_{2}$ to an individual. Note that only the IHRC-internal argument of $O p$ in (i) is represented, not the IHRC-external arguments in (ii) and (iii). ${ }^{13}$

$$
\left[_{\mathrm{CP}} \mathrm{Op} \mathrm{n}\left[\left[_{\mathrm{C}^{\prime}}\left[\ldots\left[_{\mathrm{x}_{1}:(\mathrm{vt}, \mathrm{t})}\left[\left[\mathrm{t}_{\mathrm{n}} \theta\right]\left[\mathrm{x}_{\mathrm{x}_{2}:(\mathrm{vt}, \mathrm{t})} \ldots \mathrm{IH} \ldots\right]\right]\right] \ldots\right]\right]\right]-\mathrm{no}\right.
$$

Before developing the analysis further, a word is in order regarding our syntactic assumptions. The analysis we are adopting for IHRCs shares with Kuroda (1975/76; 1992; 1999a; b) the idea that an IHRC is a nominalized sentence without any external head, with no as the nominalizer (for Kuroda, analyzed as a nominalizing complementizer). For us, an IHRC is a CP to which no is adjoined. It is a common complaint against such analyses that CPs cannot generally occur in Case-marked positions (Stowell 1981). We analyze the occurrence of no that obligatorily

11 Reviewer A finds (24d) unacceptable. The Japanese co-author of this paper finds it perfectly OK. We cannot pinpoint the reason for this disagreement, but as indicated in footnote 1 , such disagreements are not unexpected in relation to (sub-classes of) IHRCs and DHRCs.

12 A similar idea was proposed in Kratzer (1996) for introducing external arguments independently of their verbs through the head $v$, though formal details differ.

13 We employ Heim \& Kratzer's (1998) version of syntactic movement, where movement leaves behind an indexed trace but the moved element is separated from its index. This makes it possible to analyze bare indices uniformly as predicate abstractors and indexed expressions uniformly as variables. 
accompanies IHRCs as a Case-receiver, a semantically vacuous expression ${ }^{14}$ bearing the feature $[+\mathrm{N}]$, whose sole function is the syntactic function of receiving Case from some external Case assigner. In this respect, our analysis of no in IHRCs is similar to the standard analysis of English of. In nominalizations like destruction of the city, the preposition of is standardly taken to assign Case to the object. It shows up for purely syntactic reasons, having no identifiable semantic content. The difference between our analysis of the occurrence of no that marks IHRCs and the standard analysis of of lies in what syntactic role the two expressions play: of assigns case, while no receives case. In this sense the two can be thought of as complementary particles. ${ }^{15}$ What remains is to give the semantic interpretations needed to get these analyses to work.

\subsubsection{Semantics}

We base our formal analysis on the event semantics of Champollion (2015).

\subsubsection{Event semantics}

In a Champollion event semantics, all verbal projections denote event quantifiers of the same semantic type, $\langle v t, t\rangle$, where $v$ is the type of an event. The lexical specification of an event quantifier such as a verb or a verb phrase has the following form, where $\phi$ and $f$ are event predicates.

$$
\lambda f_{v t^{*}} \exists e[\phi(e) \&(\ldots \&) f(e)]
$$

Lexically specified event quantifiers do not directly assign thematic roles. Rather, their intuitive arguments combine first with thematic role assigners such as Ag(ent) or Th(eme) and only then with the event quantifier. We employ two classes of thematic role assigners. An identifying thematic role assigner $\theta_{i}$ takes an individual $x$ (of type $e$ ) as its first argument and semantically identifies that individual with the thematic role $\theta(e)$ it introduces into the event domain. A restricting thematic role assigner $\theta_{r}$ takes a property $P$ (of type et) as its first argument and semantically predicates that property of the thematic role it introduces into the event domain. Identifying thematic role assigners occur with names, individualdenoting definite descriptions, demonstratives, and strong quantifiers, assumed to undergo quantifier raising, while restricting thematic role assigners occur with indefinites and weak quantifiers, assumed to denote properties rather than individuals, as illustrated schematically below. ${ }^{16}$

14 Reviewer A objects to this characterization, noting that in the reduced form of (i), no can be replaced with yatsu 'thing', which is not semantically vacuous.

(i) Junya-wa Ayaka-ga ringo-o mui-ta (oishisoona)-no/yatsu-o tabe-ta.

Junya-TOP Ayaka-NOM apple-ACC peel-PAST delicious.looking-NL/thing-ACC eat-PAST

'Ayaka peeled some apple(s)i and Junya ate (lit. delicious-looking) it/themi.'

We follow Grosu \& Hoshi (2016, section 2) in analyzing occurrences of no that alternate with yatsu in this way as heading a light-headed EHRC. In these cases, but not in unambiguous IHRCs such as (ii) below, no/yatsu can be modified by an adjective such as oishisoona 'delicious-looking.' Our claim of semantic vacuity for no is restricted to occurrences of no in IHRCs.

The reduced version of (ii) is a well-formed IHRC with a human IH (which excludes light-headed EHRC status), and bearing Genitive Case (which excludes adverbial status). As brought out by the unacceptability of the full version, no in this example resists adjectival modification. Since yatsu appears to always be modifiable by an adjective, the non-modifiability of no in this unambiguous IHRC example points to the conclusion that it does not have the content of yatsu in IHRCs.

(ii) Junya-wa [[yuujin-ga kaigairyuugaku-ni shuppatsu-su-ru] (*shitashii)-no]-no kansoo-no Junya-TOP friend-NOM study abroad-DAT departure-do-PRES close-NL-GEN send-off-GEN tame-ni paatii-o hirai-ta. purpose-DAT party-ACC hold-PAST 'A (*close) friend of Junya's is going to leave for study abroad, and he (= Junya) held his/her sendoff party.'

15 For other analyses of no as a nominalizer (glossed below as 'NL') see Makino 1970, Nakau 1973 and Josephs 1976 , inter alia.

16 Our specific implementation of Champollion's basic semantics differs from his own in that we do not employ thematic role assigners that take quantifiers of type $\langle e t, t\rangle$ as their internal arguments. We instead assume a syntax which employs Quantifier Raising for generating interpretable structures containing quantifiers. The idea of distinguishing two ways of relating to a thematic role is taken from Landman (2016). 

a. $\quad \llbracket \theta_{\mathrm{i}} \rrbracket=\lambda \mathrm{x}_{e^{*}} \cdot \lambda \mathrm{V}_{\langle v t, t)^{*}} \lambda \mathrm{f}_{v t^{*}} \mathrm{~V}\left(\lambda \mathrm{e}_{v^{*}} \cdot \theta(\mathrm{e})=\mathbf{x} \& \mathrm{f}(\mathrm{e})\right)$
b. $\quad \llbracket \theta_{\mathrm{r}} \rrbracket=\lambda \mathbf{P}_{e t} \cdot \lambda \mathrm{V}_{\langle v t, t\rangle} \cdot \lambda \mathrm{f}_{v t} \cdot \mathrm{V}\left(\lambda \mathrm{e}_{v} \cdot \mathbf{P}(\theta(\mathrm{e})) \& \mathrm{f}(\mathrm{e})\right)$
(type $\langle e,\langle\langle v t, t\rangle,\langle v t, t\rangle\rangle\rangle)$
(type $\langle e t,\langle\langle v t, t\rangle,\langle v t, t\rangle\rangle\rangle)$

We illustrate the semantics with the sentence Ayaka-ga kukkii-o tsukut-ta (Ayaka made cookies), ignoring the interpretations of tense, aspect and case markers throughout.

$$
\begin{aligned}
& \text { [TP } \left._{\text {[Ayaka-ga Ag}}\right]_{V_{V P}} \text { [kukkii-o } \mathrm{Th}_{r} \text { ] tsukut-ta]] } \\
& \llbracket k u k k i i-o \rrbracket=\lambda \mathrm{x}_{e^{*}} \cdot \operatorname{cookies}(\mathrm{x}) \\
& \llbracket T h_{r} \rrbracket=\lambda \mathrm{P}_{e t^{*}} \cdot \lambda \mathrm{V}_{\langle v t, t\rangle^{\circ}} \lambda \mathrm{f}_{v t^{*}} \mathrm{~V}(\lambda \mathrm{e} \cdot \mathrm{P}(\mathrm{Th}(\mathrm{e})) \& \mathrm{f}(\mathrm{e})) \\
& \llbracket\left[k u k k i i-o \quad T h_{r}\right] \rrbracket=\llbracket T h_{r} \rrbracket(\llbracket k u k k i i-o \rrbracket) \\
& =\lambda \mathrm{V}_{\langle v t, t\rangle^{*}} \lambda \mathrm{f}_{v t^{*}} \mathrm{~V}(\lambda \mathrm{e} \text {. cookies(Th(e)) \& } \mathrm{f}(\mathrm{e})) \\
& \llbracket t s u k u t-t a \rrbracket=\lambda \mathrm{f}_{v t^{\prime}} \exists \mathrm{e}\left[\operatorname{make}(\mathrm{e}) \& \mathrm{f}^{\prime}(\mathrm{e})\right] \\
& \llbracket\left[_{V P}\left[k u k k i i-o \quad T h_{r}\right] \text { tsukut-ta }\right] \rrbracket=\llbracket\left[k u k k i i-o \quad T h_{r}\right] \rrbracket(\llbracket t s u k u t-t a \rrbracket) \\
& =\lambda \mathrm{f}_{v t^{*}} \cdot\left[\lambda \mathrm{f}_{v t^{\prime}} \cdot \exists \mathrm{e}\left[\text { make(e) \& } \mathrm{f}^{\prime}(\mathrm{e})\right](\lambda \mathrm{e} \cdot \operatorname{cookies}(\mathrm{Th}(\mathrm{e})) \& \mathrm{f}(\mathrm{e}))\right] \\
& =\lambda \mathrm{f}_{v t^{t}} . \exists \mathrm{e}[\mathrm{make}(\mathrm{e}) \& \operatorname{cookies}(\mathrm{Th}(\mathrm{e})) \& \mathrm{f}(\mathrm{e})] \\
& \llbracket \text { Ayaka-ga } \rrbracket=\text { ayaka } \\
& \llbracket A g_{i} \rrbracket=\lambda \mathrm{x}_{\mathrm{e}^{*}} \cdot \lambda \mathrm{V}_{\langle v t, t\rangle} \cdot \lambda \mathrm{f}_{\mathrm{vt}} \cdot \mathrm{V}(\lambda \mathrm{e} . \operatorname{Ag}(\mathrm{e})=\mathrm{x} \& \mathrm{f}(\mathrm{e})) \\
& \llbracket\left[\text { Ayaka-ga } A g_{i}\right] \rrbracket=\llbracket A g_{i} \rrbracket(\llbracket \text { Ayaka-ga } \rrbracket) \\
& =\lambda \mathrm{V}_{\langle\nu t, t\rangle} \cdot \lambda \mathrm{f}_{\mathrm{vt}} \cdot \mathrm{V}(\lambda \mathrm{e} \cdot \operatorname{Ag}(\mathrm{e})=\text { ayaka } \& \mathrm{f}(\mathrm{e})) \\
& \left.\llbracket L_{T P}\left[\text { Ayaka-ga } A g_{i}\right]\left[_{V P}\left[\text { kukkii-o } T h_{r}\right] \text { tsukut-ta }\right]\right] \rrbracket \\
& =\llbracket\left[\text { Ayaka-ga } A g_{i}\right] \rrbracket\left(\llbracket\left[_{V P}\left[k u k k i i-o ~ T h_{r}\right] \text { tsukut-ta }\right] \rrbracket\right) \\
& =\left[\lambda \mathrm{V}_{\langle v t, t\rangle^{*}} \lambda \mathrm{f}_{\mathrm{vvt}} \cdot \mathrm{V}(\lambda \mathrm{e} \cdot \operatorname{Ag}(\mathrm{e})=\text { ayaka } \& \mathrm{f}(\mathrm{e}))\right] \\
& \left(\lambda f_{\mathrm{vt}} \cdot \exists e[\text { make(e) \& cookies(Th(e)) \& f(e)]) }\right. \\
& =\lambda \mathrm{f}_{\mathrm{vt}} \cdot \exists \mathrm{e}[\mathrm{make}(\mathrm{e}) \& \operatorname{cookies}(\mathrm{Th}(\mathrm{e})) \& \operatorname{Ag}(\mathrm{e})=\text { ayaka } \& \mathrm{f}(\mathrm{e})]
\end{aligned}
$$

The result of the semantic composition is once again an event quantifier, of type $\langle v t, t\rangle$. To create an appropriate meaning for an utterance, one that can be true or false, the sentence is combined with a closure operator ${ }^{17}$ in SpecCP. The closure operator applies to an event and gives back a proposition that is always true, indicated below as the proposition true.

$$
\begin{aligned}
& \llbracket \text { closure } \rrbracket=\lambda \mathrm{e}_{v} \text {. true } \\
& \llbracket\left[_{C P} \text { closure }\left[_{T P}\left[\text { Ayaka-ga } \mathrm{Ag}_{i}\right]\left[_{V P}\left[k \text { ukkii-o } \mathrm{Th}_{r}\right] \text { tsukut-ta]}\right]\right] \rrbracket\right. \\
& \left.=\llbracket \complement_{T P}\left[\text { Ayaka-ga Ag} g_{i}\right]\left[_{V P}\left[\text { kukkii-o } T h_{r}\right] \text { tsukut-ta }\right]\right] \rrbracket(\llbracket \text { closure } \rrbracket) \\
& =\left[\lambda \mathrm{f}_{\mathrm{vt}} \cdot \exists \mathrm{e}[\mathrm{make}(\mathrm{e}) \& \operatorname{cookies}(\mathrm{Th}(\mathrm{e})) \& \mathrm{Ag}(\mathrm{e})=\text { ayaka } \& \mathrm{f}(\mathrm{e})]\right]\left(\lambda \mathrm{e}_{\mathrm{v}} \cdot \text { true }\right) \\
& =\exists \mathrm{e}[\mathrm{make}(\mathrm{e}) \& \operatorname{cookies}(\mathrm{Th}(\mathrm{e})) \& \mathrm{Ag}(\mathrm{e})=\text { ayaka \& true }] \\
& \approx \exists \text { e [make(e) \& cookies(Th(e)) \& Ag(e)=ayaka] }
\end{aligned}
$$

The equivalence between the last two lines derives from the fact that for any proposition $p, p \&$ true is true iff $p$ is true. An utterance of the sentence is then predicted to be true iff there is a making event whose theme has the property of being cookies and whose agent is Ayaka.

\subsubsection{IHRC semantics}

We follow Landman (2016) in analyzing IHRCs as involving disclosure. Unlike Landman, we implement disclosure through use of an additional identifying thematic role assigner. The sentence Ayaka-ga kukkii-o tsukut-ta analyzed in the previous section can then be turned into an IHRC with kukkii as its IH as follows:

$$
\left[_{\mathrm{CP}} \mathrm{Op}\left[{ }_{\mathrm{X}} 1 \ldots\left[\left[\mathrm{t}_{1} \mathrm{Th}_{\mathrm{i}}\right]\left[_{\mathrm{TP}} \text { Ayaka-ga kukki-o tsukut-ta }\right]\right]\right]\right]
$$

17 Note that this closure operator is not an Existential Closure operator, since it does not introduce an existential quantifier. Its role is to turn an event quantifier into something that is true or false, something that is only needed at the utterance level and never in the internal semantic composition. 
The bare numeral 1 is a predicate abstractor, abstracting over the interpretation of the trace $t_{1}$ that combines with the identifying theme role assigner $T h_{i}{ }^{18}$ The interpretation of this predicate abstraction, i.e. of the node labeled $X$, is the following, where the contribution of the additional theme role assigner is in bold.

$$
\llbracket X \rrbracket=\lambda \mathrm{x}_{\mathrm{e}} \cdot \lambda \mathrm{f}_{\mathrm{vt}} \cdot \exists \mathrm{e}[\mathrm{make}(\mathrm{e}) \& \operatorname{cookies}(\mathrm{Th}(\mathrm{e})) \& \operatorname{Ag}(\mathrm{e})=\text { ayaka } \& \operatorname{Th}(\mathrm{e})=\mathbf{x} \& \mathrm{f}(\mathrm{e})]
$$

For any event e and thematic role $\theta$ having e in its domain, we assume that $\theta(e)$ is unique. This is our characterization of the $\theta$-criterion. Being unique does not entail having a unique description, however. Just like an individual can be identified as Mary and as being 6 feet tall at the same time, so too the unique entity that is $\theta(e)$ can be identified as a particular object and as being cookies, being tasty, or as having any number of additional properties. Combining a verbal predicate with multiple instances of a single thematic role assigner $\theta$ adds additional information about the unique entity $\theta(\mathrm{e})$. As long as these properties are mutually consistent, the $\theta$-criterion as we conceive it is satisfied. In (31), the theme of the existentially quantified event $\mathrm{e}$ is simultaneously identified as cookies and as identical to $\mathrm{x}, \mathrm{x}$ a variable. These two properties are mutually consistent provided that the value ultimately assigned to $\mathrm{x}$ is cookies.

What remains is to give an analysis of $O p$ in (30). To incorporate Kuroda Relevance into our analysis of IHRCs, we take advantage of the fact that an IHRC functions as an argument of a structurally higher predicate in a structure like the following, where $\mathrm{H}^{*}$ is a projection of a lexical event quantifier such as a verb.

$$
\text { [[IHRC } \left.\left.\theta_{\mathrm{i}}\right] \mathrm{H}^{*}\right]
$$

We take the denotation of the IHRC to be the main semantic function of the structure in (32), giving a complex semantic interpretation to $O p$ that in addition to generating an IHRC reference also imposes a Kuroda Relevance requirement on the main IHRC and $\mathrm{H}^{*}$ events.

We formalize Kuroda Relevance informally as a relation between two events:

\section{Kuroda Relevance relation (KR):}

$\mathrm{KR}\left(\mathrm{e}, \mathrm{e}^{\prime}\right)$ is true iff e and $\mathrm{e}^{\prime}$ can be interpreted as part of a single natural eventuality.

In order to check for Kuroda Relevance, we need to be able to extract relevant events from the IHRC and from $\mathrm{H}^{*}$ in (32). We accomplish this with the following event disclosure function, with $e_{i}$ a free variable.

$$
\text { event disclosure function: } \lambda \mathrm{e}_{\mathrm{v}} \cdot \mathrm{e}=\mathrm{e}_{\mathrm{i}}
$$

We build this function into the semantics of the IHRC operator Op twice, once for the IHRCreference argument and once for the $\mathrm{H}^{*}$ argument. Our semantics for $\mathrm{Op}$ is given below.

$$
\begin{aligned}
& \llbracket O p \rrbracket=\quad \lambda P_{\langle e,\langle v t, t\rangle} \cdot \lambda \theta_{\langle e,\langle\langle v t, t\rangle,\langle v t, t\rangle\rangle\rangle^{\prime}} \cdot \lambda Q_{\langle v t, t\rangle^{*}} \lambda f_{v t^{*}} \\
& \exists \mathrm{e}_{1}, \mathrm{e}_{2}\left[\theta\left(\sigma\left(\lambda \mathrm{x}_{\mathrm{e}} \cdot P(\mathrm{x})\left(\lambda \mathrm{e}_{v^{*}} \mathrm{e}=\mathrm{e}_{1}\right) \& \mathrm{KR}\left(\mathrm{e}_{1}, \mathrm{e}_{2}\right)\right)\right)(Q)\left(\lambda \mathrm{e}_{v^{*}} \mathrm{e}=\mathrm{e}_{2} \& \mathrm{f}(\mathrm{e})\right)\right]
\end{aligned}
$$

The $P$ argument is the first argument of $O p$, representing the interpretation of the IHRC-internal sister of $O p$. For the IHRC in (30) above this is the interpretation given in (31), a function that takes an individual and an event property as arguments and gives back something that is true or false. We give $P$ an individual variable $x$ as its first argument and our event disclosure function as its second, conjoin the result with our KR relation, and then re-abstract over $x$. This gives us two things: a 1-place predicate of type et that can serve as the argument of Landman's $\sigma$ operator to generate an obligatorily definite reference - the IHRC reference - and an

18 Under the semantics we adopt, interpretation implicitly involves two steps: translation from the object language into a formula of logic, and interpretation of the logic. Though we adopt Heim \& Kratzer's syntax of predicate abstraction, since their semantics is one that directly interprets English expressions without first translating them into an intermediate logic, our implementation of the semantics of predicate abstraction necessarily differs from theirs. We adopt the following as our rule for the logical translation of an expression consisting of a bare numeral $i$ and another syntactic expression $\alpha$ :

$$
\llbracket i \alpha \rrbracket^{g}=\lambda \mathrm{x} . \llbracket \alpha \rrbracket^{g[\mathrm{i} / \mathrm{x}]} \text {, where } \mathrm{g}[\mathrm{i} / \mathrm{x}] \text { is exactly like } \mathrm{g} \text { except at most that } \mathrm{g}[\mathrm{i} / \mathrm{x}](\mathrm{i})=\mathrm{x} \text {. }
$$

Formally, application of predicate abstraction to an expression $\alpha$ requires that $\alpha$ be translated with respect to a variable assignment function. We suppress variable assignments here and throughout for readability. We also refer to the logical translation of an expression as its interpretation throughout, though strictly speaking the formulas given should all be understood as logical translations that themselves need to be interpreted. 
occurrence of the event variable $e_{1}$ that is ultimately bound by the existential quantifier in the interpretation of $\mathrm{Op}$. Note that Kuroda Relevance in this analysis ends up as a presupposition: the IHRC only generates an IHRC reference when the KR relation is satisfied by the pair of events it operates on. Note also that the IHRC-internal event required to stand in the KR relation will always be the main event of the $P$ argument, i.e. the highest event internal to the IHRC.

The $\theta$ argument of $O p$ in (35), its second argument, corresponds to the thematic role assigner associated with the higher event quantifier that selects the IHRC, and the $Q$ argument of $O p$ corresponds to that higher event quantifier, $\mathrm{H}^{*}$ in (32) above. As always, $\theta$ is the glue that combines an event quantifier with its argument. It combines first with the IHRC reference, and then with the $Q$ argument, forming another event quantifier in which the IHRC reference has been entered into a thematic role. The result is a function that takes an event property as argument and gives back something that is true or false. As its event property argument, it is given our event disclosure function conjoined with the Champollionian glue $f(e)$ that, via abstraction over $f$, allows the result of combining $O p$ with its three arguments to continue to play the role of an event quantifier in the remainder of the sentence. The event variable $e_{2}$ introduced here by the event disclosure function occurs as the second argument of our KR relation and is existentially bound. Since this variable is identified with the main event of the $Q$ argument, the IHRC-external event required to stand in the KR relation will always be the main event of whatever fills this $Q$ argument, i.e. it will always be the main event of the predicate that the IHRC is an argument of.

We illustrate the semantics of $O p$ with the following sentence.

$$
\begin{aligned}
& \text { Junya-wa } \quad \text { Ayaka-ga kukkii-o tsukut-ta-no]-o tabemashi-ta. } \\
& \text { Junya-TOP Ayaka-NOM cookies-ACC make-PAST-NL-ACC eat-PAST } \\
& \text { 'Ayaka made cookies, and Junya ate them.' }
\end{aligned}
$$

We assume the following structure for the sentence, suppressing the internal structure of $\mathrm{TP}_{3}$.

$$
\begin{aligned}
& {\left[_ { C P _ { 1 } } \text { closure } \left[_ { T P _ { 1 } } \left[_ { V P } [ _ { \theta _ { 2 } } \text { Junya-wa } A g _ { i } ] \left[_ { V ^ { \prime } } \left[_ { \theta _ { 1 } } \left[_ { C P _ { 2 } } O p \left[_ { X } 1 \left[_ { T P _ { 2 } } [ _ { \theta _ { 3 } } t _ { 1 } T _ { i } ] \left[_{T P_{3}}\right.\right.\right.\right.\right.\right.\right.\right.\right. \text { Ayaka-ga }} \\
& \text { kukkii-o tsukut-ta]]]]-no-o } \left.\mathrm{Th}_{i}\right] \text { [V }_{V} \text { tabemashi-ta]]]]] }
\end{aligned}
$$

The compositional interpretation is given below, where the interpretation of $X$ is taken from (31) above.

$$
\begin{aligned}
& \llbracket X \rrbracket=\lambda \mathrm{x}_{\mathrm{e}} \cdot \lambda \mathrm{f}_{\mathrm{vt}} \cdot \exists \mathrm{e}[\mathrm{make}(\mathrm{e}) \& \operatorname{cookies}(\mathrm{Th}(\mathrm{e})) \& \operatorname{Ag}(\mathrm{e})=\operatorname{ayaka} \& \mathrm{Th}(\mathrm{e})=\mathrm{x} \& \mathrm{f}(\mathrm{e})] \\
& \llbracket C P_{2} \rrbracket=\llbracket O p \rrbracket(\llbracket X \rrbracket) \\
& =\left[\lambda P_{\langle e,\langle v t, t\rangle\rangle} \cdot \lambda \theta_{\langle e,\langle\langle v t, t\rangle,\langle v t, t\rangle\rangle)} \cdot \lambda Q_{\langle v t, t\rangle^{*}} \lambda \mathrm{f}_{v t^{*}}\right. \\
& \left.\exists \mathrm{e}_{1}, \mathrm{e}_{2}\left[\theta\left(\sigma\left(\lambda \mathrm{x}_{\mathrm{e}} \cdot P(\mathrm{x})\left(\lambda \mathrm{e}_{v^{\prime}} \cdot \mathrm{e}=\mathrm{e}_{1}\right) \& \mathrm{KR}\left(\mathrm{e}_{1}, \mathrm{e}_{2}\right)\right)\right)(Q)\left(\lambda \mathrm{e}_{v} \cdot \mathrm{e}=\mathrm{e}_{2} \& \mathrm{f}(\mathrm{e})\right)\right]\right] \\
& \left(\lambda \mathrm{x}_{\mathrm{e}} \cdot \lambda \mathrm{f}_{\mathrm{vt}} \cdot \exists \mathrm{e}[\mathrm{make}(\mathrm{e}) \& \operatorname{cookies}(\mathrm{Th}(\mathrm{e})) \& \operatorname{Ag}(\mathrm{e})=\text { ayaka } \& \mathrm{Th}(\mathrm{e})=\mathrm{x} \& \mathrm{f}(\mathrm{e})]\right) \\
& =\lambda \theta_{\langle e,\langle\langle v t, t\rangle,\langle v t, t\rangle\rangle)^{\prime}} \cdot \lambda Q_{\langle v t, t\rangle} \cdot \lambda f_{\langle v t, t\rangle^{*}} \\
& \exists \mathrm{e}_{1}, \mathrm{e}_{2}\left[\theta \left(\sigma \left(\lambda \mathrm{x}_{\mathrm{e}} \cdot \exists \mathrm{e}[\mathrm{make}(\mathrm{e}) \& \operatorname{cookies}(\mathrm{Th}(\mathrm{e})) \& \operatorname{Ag}(\mathrm{e})=\text { ayaka } \& \mathrm{Th}(\mathrm{e})=\mathrm{x} \&\right.\right.\right. \\
& \left.\left.\left.\left.\mathrm{e}=\mathrm{e}_{1}\right] \& \mathrm{KR}\left(\mathrm{e}_{1}, \mathrm{e}_{2}\right)\right)\right)(Q)\left(\lambda \mathrm{e}_{v} \cdot \mathrm{e}=\mathrm{e}_{2} \& \mathrm{f}(\mathrm{e})\right)\right] \\
& \llbracket T h_{i} \rrbracket=\lambda \mathrm{x}_{e^{\prime}} \cdot \lambda \mathrm{V}_{\langle v t, t)^{*}} \cdot \lambda \mathrm{f}_{v t^{\prime}} \cdot \mathrm{V}\left(\lambda \mathrm{e}_{v^{\prime}} \cdot \operatorname{Th}\left(\mathrm{e}^{\prime}\right)=\mathrm{x} \& \mathrm{f}\left(\mathrm{e}^{\prime}\right)\right) \\
& \llbracket \theta_{1} \rrbracket=\llbracket C P_{2} \rrbracket\left(\llbracket T h_{i} \rrbracket\right) \\
& =\lambda Q_{\langle v t, t\rangle} \cdot \lambda \mathrm{f}_{\langle v t, t\rangle^{*}} \exists \mathrm{e}_{1}, \mathrm{e}_{2}\left[Q \left(\lambda \mathrm{e}^{\prime}{ }_{v^{*}} \operatorname{Th}\left(\mathrm{e}^{\prime}\right)=\sigma\left(\lambda \mathrm{x}_{\mathrm{e}} \cdot \exists \mathrm{e}[\text { make(e) \& cookies(Th(e)) \& }\right.\right.\right. \\
& \left.\left.\left.\left.\operatorname{Ag}(e)=\text { ayaka } \& \operatorname{Th}(e)=x \& \quad e=e_{1}\right] \& \operatorname{KR}\left(e_{1}, e_{2}\right)\right) \& e^{\prime}=e_{2} \& f\left(e^{\prime}\right)\right)\right] \\
& \llbracket V \rrbracket=\lambda \mathrm{f}^{\prime}{ }_{\mathrm{vt}}^{*} \exists \mathrm{e}^{\prime}\left[\operatorname{eat}\left(\mathrm{e}^{\prime}\right) \& \mathrm{f}^{\prime}\left(\mathrm{e}^{\prime}\right)\right] \\
& \llbracket V^{\prime} \rrbracket=\llbracket \theta_{1} \rrbracket(\llbracket V \rrbracket) \\
& =\lambda \mathrm{f}_{\langle v, t\rangle^{\circ}} \cdot \exists \mathrm{e}_{1}, \mathrm{e}_{2}\left[\exists \mathrm { e } ^ { \prime } \left[\operatorname{eat}\left(\mathrm{e}^{\prime}\right) \& \operatorname{Th}\left(\mathrm{e}^{\prime}\right)=\sigma\left(\lambda \mathrm{x}_{\mathrm{e}} \cdot \exists \mathrm{e}[\operatorname{make}(\mathrm{e}) \& \operatorname{cookies}(\mathrm{Th}(\mathrm{e})) \&\right.\right.\right. \\
& \left.\left.\left.\left.\operatorname{Ag}(e)=\text { ayaka } \& \operatorname{Th}(e)=x \& e=e_{1}\right] \& \operatorname{KR}\left(e_{1}, e_{2}\right)\right) \& e^{\prime}=e_{2} \& f\left(e^{\prime}\right)\right)\right] \\
& \llbracket A g_{i} \rrbracket=\lambda \mathrm{x}_{e^{*}} \cdot \lambda \mathrm{V}_{\langle v t, t} \cdot \lambda \mathrm{f}_{v t^{*}} \cdot \mathrm{V}\left(\lambda \mathrm{e}^{\prime} \cdot \operatorname{Ag}\left(\mathrm{e}^{\prime}\right)=\mathrm{x} \& \mathrm{f}\left(\mathrm{e}^{\prime}\right)\right) \\
& \llbracket \theta_{2} \rrbracket=\llbracket A g_{i} \rrbracket(\llbracket \text { Junya } \rrbracket) \\
& =\lambda \mathrm{V}_{\left\langle v t, t t^{*}\right.} \lambda \mathrm{f}_{v t^{*}} \cdot \mathrm{V}\left(\lambda \mathrm{e}_{v^{\prime}} \cdot \operatorname{Ag}\left(\mathrm{e}^{\prime}\right)=\text { junya } \& \mathrm{f}\left(\mathrm{e}^{\prime}\right)\right)
\end{aligned}
$$




$$
\begin{aligned}
& \llbracket T P_{1} \rrbracket=\llbracket V P \rrbracket=\llbracket \theta_{2} \rrbracket\left(\llbracket V^{\prime} \rrbracket\right) \\
& =\lambda \mathrm{f}_{v t^{*}} \exists \mathrm{e}_{1}, \mathrm{e}_{2}\left[\exists \mathrm { e } ^ { \prime } \left[\mathrm{eat}\left(\mathrm{e}^{\prime}\right) \& \mathrm{Th}\left(\mathrm{e}^{\prime}\right)=\sigma\left(\lambda \mathrm{x}_{\mathrm{e}} \cdot \exists \mathrm{e}[\text { make(e) \& cookies(Th(e)) \& }\right.\right.\right. \\
& \left.\left.\operatorname{Ag}(e)=\text { ayaka } \& \operatorname{Th}(e)=x \& e=e_{1}\right] \& \operatorname{KR}\left(e_{1}, e_{2}\right)\right) \& e^{\prime}=e_{2} \& \operatorname{Ag}\left(e^{\prime}\right)=\text { junya } \\
& \text { \& } \left.\left.\mathrm{f}\left(\mathrm{e}^{\prime}\right)\right)\right] \text { ] } \\
& \llbracket C P_{1} \rrbracket=\llbracket T P_{1} \rrbracket(\llbracket \text { closure } \rrbracket) \\
& =\exists \mathrm{e}_{1}, \mathrm{e}_{2}\left[\exists \mathrm { e } ^ { \prime } \left[\mathrm{eat}\left(\mathrm{e}^{\prime}\right) \& \mathrm{Th}\left(\mathrm{e}^{\prime}\right)=\sigma\left(\lambda \mathrm{x}_{\mathrm{e}} \cdot \exists \mathrm{e}[\text { make(e) \& cookies(Th(e)) \& }\right.\right.\right. \\
& \left.\left.\operatorname{Ag}(\mathrm{e})=\text { ayaka } \& \mathrm{Th}(\mathrm{e})=\mathrm{x} \& \mathrm{e}=\mathrm{e}_{1}\right] \& \mathrm{KR}\left(\mathrm{e}_{1}, \mathrm{e}_{2}\right)\right) \& \mathrm{e}^{\prime}=\mathrm{e}_{2} \& \\
& \left.\left.\left.\operatorname{Ag}\left(\mathrm{e}^{\prime}\right)=\text { junya \& true }\right)\right]\right] \\
& \approx \exists \mathrm{e}_{1}, \mathrm{e}_{2}\left[\exists \mathrm { e } ^ { \prime } \left[\operatorname{eat}\left(\mathrm{e}^{\prime}\right) \& \operatorname{Th}\left(\mathrm{e}^{\prime}\right)=\sigma\left(\lambda \mathrm{x}_{\mathrm{e}} \cdot \exists \mathrm{e}[\text { make(e) \& cookies(Th(e)) \& }\right.\right.\right. \\
& \left.\left.\operatorname{Ag}(\mathrm{e})=\text { ayaka \& } \mathrm{Th}(\mathrm{e})=\mathrm{x} \& \mathrm{e}=\mathrm{e}_{1}\right] \& \mathrm{KR}\left(\mathrm{e}_{1}, \mathrm{e}_{2}\right)\right) \& \mathrm{e}^{\prime}=\mathrm{e}_{2} \& \\
& \left.\operatorname{Ag}\left(e^{\prime}\right)=\text { junya] }\right]
\end{aligned}
$$

The final formula is true iff there are two events, $e_{1}$ and $e_{2}$, such that $e_{1}$ is a making of cookies by Ayaka, and $e_{2}$ is an eating by Junya of the cookies involved in $e_{1}$ on the presupposition that $\mathrm{e}_{1}$ and $\mathrm{e}_{2}$ satisfy Kuroda Relevance.

As noted, our analysis of IHRCs predicts that the KRC has to be satisfied by the highest event in the IHRC and the main event of the event quantifier that the IHRC reference is directly thematically related to. In the case where this event quantifier is contributed by a relational noun such as shurui $(=k i n d)$, we predict that the KRC has to be satisfied locally by the IHRC and that relational noun. The following examples suggest that this prediction is borne out. ${ }^{19}$

$$
\begin{aligned}
& \text { a. \#[Ayaka-ga kukkii-o tsukut-ta-no]-ga chokochippu kukkii da. } \\
& \text { Ayaka-NOM cookies-ACC make-PAST-NL-NOM chocolate.chip cookie COP } \\
& \text { 'Ayaka made cookies, and they are chocolate chip cookies.' }
\end{aligned}
$$

b. [[Ayaka-ga kukkii-o tsukut-ta-no]-no shurui]-ga chokochippu Ayaka-NOM cookies-ACC make-PAST-NL-GEN kind-NOM chocolate-GEN kukkii da.

cookie COP

'Ayaka made cookies, and their kind is chocolate chip cookies.'

c. [[Ayaka-ga [e] tsukut-ta] kukkii]-ga chokochippu kukkii da. Ayaka-NOM gap make-PAST cookies-NOM chocolate-GEN cookie COP 'The cookies Ayaka made are chocolate chip cookies.'

The unacceptability of (39a) suggests that the main events of the IHRC Ayaka-ga kukkii-o tsukutta-no and of the matrix clause chokochippu kukkii da do not satisfy the KRC. This is corroborated by the fact that the EHRC version of the sentence in (39c) is perfectly acceptable. (39b) differs from (39a) in that the IHRC in (39b) acts as the possessor in a nominal headed by shurui. The fact that (39b) is acceptable shows that the fact that the IHRC and the matrix predicate do not satisfy the KRC makes no difference to the acceptability of the sentence. It also suggests that the relation between the IHRC and the possessed noun shurui does satisfy the KRC. ${ }^{20}$

\subsubsection{Explanations}

The necessary movement of $O p$ from a position in a sister to the minimal clause containing the IH to the highest position in the IHRC accounts for the island sensitivity of IHRCs in exactly the same way as Landman's (2016) analysis. Definiteness, as highlighted earlier, is accounted for through the stipulated inclusion of Landman's $\sigma$ operator in the interpretation of Op. KRC effects come from explicitly requiring two events in the semantics of $O p$ to satisfy a KR relation, another stipulation of the analysis. Which two events get related derives from the requirement that the events be the main events of two of the semantic arguments of $O p$. This makes it impossible for the IHRC-internal event to be anything but the main event of the sister of $O p$, and makes it impossible for the IHRC-external event to be anything but the event of the predicate that selects the IHRC.

19 We cannot strengthen suggest to show until we have a full understanding of the KRC that predicts the distinction in (39a,b), an understanding that we currently lack. 
Regarding integration, as noted in section 1, we take a construction to exhibit integration if it may be contained within a single illocutionary unit. Non-restrictive relative clauses do not meet this requirement, but IHRCs, as analyzed above, do. The compositionally derived semantic interpretation of (36) given in (38), for example, can easily be uttered as a single assertion, questioned in a single question, or have any part of it negated with the addition of a single negation.

As the analysis stands, it does not block IHRCs with individual-identifying IHs. We achieve the desired blocking by only allowing a single identifying thematic role assigner per event quantifier. Identifying thematic role assigners, recall, add conjuncts of the form $\theta(e)=x$ to an event quantifier, not merely restricting $\theta(e)$ like restrictive thematic role assigners do but identifying a specific individual referent for $\theta(e)$. Blocking event quantifiers from combining with multiple occurrences of a single identifying thematic role assigner $\theta_{i}$ makes it impossible to add an occurrence of $\left[O p \theta_{i}\right]$ to an event quantifier that has already combined with some other occurrence of the form $\left[x \theta_{i}\right]$, which thereby makes it impossible to generate an IHRC with an individual-identifying $\mathrm{IH}$.

For definite descriptions, we distinguish those associated with a known referent from those merely known to have a unique referent. The former we analyze as of type $e$ or $\langle e t, t\rangle$ and relate to an event via an identifying thematic role. The latter we analyze as of type et and relate to an event via a relational thematic role. This makes it possible to generate an IHRC with a definite description as IH whenever that description does not have a known referent, a possibility illustrated in the following sentence.

$$
\begin{aligned}
& \text { Sono uchuuhikooshi-wa [[uchuu-de mottomo mitsudo-ga takai wakusei-ga } \\
& \text { that astronaut-TOP universe-in most density-NOM high planet-NOM } \\
& \text { me-no mae-ni chikazuitekita]-no]-no hyoomen]-o kansatsushi-ta } \\
& \text { eye-GEN before-DAT get.closer-NL-GEN surface-ACC observe-PAST } \\
& \text { 'The densest planet in the universe was coming before an astronaut and the } \\
& \text { astronaut observed its surface.' }
\end{aligned}
$$

We can know that there is a unique densest planet without knowing which planet that is. The description uchuu-de mottomo mitsudo-ga takai wakusei (the densest planet in the universe) can then be analyzed as a type et expression and its denotation can be entered into the event structure of chikazuitekita (get closer) with a relational thematic role assigner. This makes it possible to add a separate identifying role assigner to the same predicate, rendering it possible to generate an IHRC with this description as IH.

\subsection{DHRCs}

There are few analyses of DHRCs in the literature, EG being one notable for its formal explicitness.

\subsubsection{Erlewine \& Gould (2016)}

EG attempt to unify EHRCs, IHRCs and DHRCs. They analyze the three constructions as syntactically derived from a single underlying representation, and as differing only (i) in which of two operations applies, Trace Conversion (TC) or Inverse Trace Conversion (ITC), and (ii) in whether the relevant operation applies before or after Spell-Out. The appeal of such an approach is obvious: it aims to account for the properties of all three constructions using only independently available tools. The challenge such an approach faces is in accounting for systematic differences among the three constructions, and - as already pointed out by Grosu \& Hoshi (2018) - in providing an analysis for all the varieties of EHRCs, IHRCs and DHRCs found in Japanese.

For EG, all three relative clause constructions are constructed from a proto relative clause, derived by copying an RC-internal expression and merging the RC with the NP inside that copied expression. For a relative clause based on the sentence Ayaka-ga kukkii-o 20-mai tsukut-ta (= Ayaka made 20 cookies), their proto relative clause structure is the following:

$$
\left[_ { D P } \left[_ { N P } \left[_ { C P } \text { Ayaka [[ } \left[_{D P}\left[_{N P} \text { kukkii] 20-mai] tsukut-ta] } \lambda_{i}\right]\right.\right.\right.\right. \text { kukkii] 20-mai] }
$$


One of two operations can apply to (41): TC or ITC. TC adds a variable $x$ to the RC-internal kukkii, equates $x$ with the reference of kukkii, converts everything in the lower DP copy that is not part of the NP into the determiner THE, and binds $x$ with $\lambda_{i}$, as in (42a). ITC adds a variable $X$ to the RC-internal kukkii, analyzes the reference of kukkii as a part of $X$, binds $X$ with $\lambda_{i}$, and converts everything in the higher copy that is not part of the NP into the determiner THE, as in (42b). ${ }^{21}$

$$
\begin{aligned}
& \text { a. } \left.\left.\quad\left[_{\mathrm{DP}}\left[_{\mathrm{NP}}\left[\mathrm{C}_{\mathrm{CP}} \text { Ayaka }\left[\mathrm{C}_{\mathrm{DP}} \mathrm{C}_{\mathrm{NP}} \text { kukkii } \boldsymbol{\lambda y} \cdot \boldsymbol{y}=\boldsymbol{x}\right] \mathrm{THE}\right] \text { tsukut-ta }\right] \boldsymbol{\lambda x}\right] \text { kukkii }\right] \text { 20-mai }\right] \\
& (=\text { (41) plus Trace Conversion (TC)) } \\
& \text { b. } \quad\left[_{D P}\left[_{N P}\left[{ }_{C P} \text { Ayaka }\left[\left[_{D P}\left[_{N P} \text { kukkii } \lambda y \cdot y \sqsubseteq X\right] 20 \text {-mai }\right] \text { tsukut-ta }\right] \lambda X\right] \text { kukkii }\right] \text { THE }\right] \\
& (=(41) \text { plus Inverse Trace Conversion (ITC)) }
\end{aligned}
$$

TC and ITC can each apply either before or after Spell-Out. If they apply after Spell-Out, the structure that gets spelled out is that in (41). EG take the RC-internal copy and the RC-external copy of kukkii 20-mai to be formally the same object in (41), which can only be spelled out in one position. If this object is spelled out RC-internally the result is an IHRC, and if spelled out RC-externally the result is an EHRC. EG additionally stipulate that the position in which this object is spelled out at PF is the position in which the quantificational material is interpreted at LF. ${ }^{22}$ This stipulation essentially requires application of TC in the EHRC case, generating the LF representation in (42a), and application of ITC in the IHRC case, generating the LF representation in (42b).

When TC and ITC apply before Spell-Out, the structures that get spelled out are those in (42). In these cases, the two copies of kukkii presumably do not count formally as the same object, making it possible for both copies to be pronounced without violating linearization requirements. The combination of THE with kukkii in (42b) is taken to be conventionally spelled out as sono kukkii. The parallel combination in (42a) is stipulated to not be pronounced at all.

Regarding the KRC, EG stipulate that "pronunciation of the lower copy nominal - the property shared by [IHRCs] and DHRCs, to the exclusion of [EHRCs] - is licensed by satisfaction of the Relevancy Condition." They thus predict that KRC effects should arise in both of these constructions.

\subsubsection{Challenges for Erlewine \& Gould (2016)}

If EG's analysis were empirically adequate, the many stipulations needed to make it work could be accepted as a necessary cost for success. The analysis is not, however, empirically adequate. In this section we outline empirical problems for EG's analysis that any analysis of DHRCs must explain.

\subsubsection{Incorrect denotation with quantificational IH}

EG's analysis makes incorrect predictions for the interpretation of DHRCs with a quantificational IH such as the following:

$$
\begin{aligned}
& \text { [Context: Ayaka-ga kukkii-o 20-mai tsukut-ta.] } \\
& \text { Ayaka-NOM cookies-ACC 20-CL make-PAST } \\
& \text { Ayaka made } 20 \text { cookies. } \\
& \text { Junya-wa [[Yoko-ga kore-kara hotondo-no kukkii-o reezooko-ni } \\
& \text { Junya-TOP Yoko-NOM this-after almost.all-GEN cookies-ACC fridge-DAT } \\
& \text { ire-ru] sono kukkii]-o zenbu paatii-ni motteik-u tsumori da. } \\
& \text { put.in-PRES those cookies-ACC all party-DAT bring-PRES intention COP } \\
& \text { 'After this, Yoko will put most of the cookies into the fridge, and Junya } \\
& \text { intends to bring those cookies to the party.' }
\end{aligned}
$$

\footnotetext{
21 The structures in (42) mix syntax and semantics in an illegitimate way, placing semantic interpretations italicized in (42) - directly into syntactic trees. We take the semantic expressions to be EG's shorthand for implicit pieces of syntax that have the semantic expressions as their interpretation.
}

22 This stipulation, taken from Bobaljik (1995), is given in the form of his Minimize Mismatch constraint:

Minimize Mismatch: Pronounce the copy of an element which is mapped to the quantificational structure. 
The second sentence in this example is ambiguous. On one reading it requires Junya to bring all 20 of the cookies that Ayaka made. On the other reading it only requires Junya to bring all of the cookies that Yoko puts in the fridge. EG's analysis at best accounts for the first of these readings.

EG derive DHRCs by applying ITC prior to Spell-Out, generating the following LF representation for the DHRC in (43):

$$
\left[\left[\left[\text { Yoko }\left[\left[_{\mathrm{DP}} \text { hotondo }\left[_{\mathrm{NP}} \text { kukkii } \lambda y . y \sqsubseteq X\right]\right] \text { reezooko-ni ire-ru] } \lambda X\right]\right.\right.\right. \text { kukkii] THE] }
$$

Since EG do not give an explicit semantics for interpreting quantified expressions, it is impossible to derive a precise prediction of the interpretation of this structure. However, based on their claimed interpretations of similar examples using hanbun (= half), we take the above analysis to result in the DHRC referring to the maximal set of contextually salient cookies of which Yoko will put most into the fridge. That is, if Yoko is to put 18 out of the 20 cookies Ayaka made into the fridge, this DHRC denotes the 20 cookies, not just the 18. EG's analysis does not generate an interpretation of the sentence in which the DHRC denotes the 18 cookies.

If we look more closely at the interpretation of (43), things look even worse for EG. Observationally, on the interpretation in which the DHRC of (43) denotes 20 cookies, the relative clause is interpreted appositively. In our terminology, this means it is not integrated. This can be shown by replacing Yoko with dare $(=w h o)$. This substitution renders the DHRC unambiguous, only possibly referring to all of the cookies put into the fridge, not to the 20 that Ayaka made (unless all 20 are put into the fridge, a possibility allowed semantically with hotondo but pragmatically dis-preferred).

$$
\begin{aligned}
& \text { [Context: Ayaka-ga kukkii-o 20-mai tsukut-ta.] } \\
& \text { Ayaka-NOM cookies-ACC 20-CL make-PAST } \\
& \text { Ayaka made } 20 \text { cookies. }
\end{aligned}
$$

Junya-wa [[dare-ga kore-kara hotondo-no kukkii-o reezooko-ni Junya-TOP who-NOM this-after almost-all-GEN cookies-ACC fridge-DAT ire-ru] sono kukkii]-o zenbu paatii-ni motteik-u tsumori na no? put-in-PRES those cookies-ACC all party-DAT bring-PRES intention COP Q 'After this, who will put most of the cookies into the fridge such that Junya will bring those cookies to the party?'

If EG's analysis of the 20 cookie reading is to be maintained, the movement that creates the proto relative clause must then be capable of moving an expression from inside an appositive relative clause to outside that clause, a dubious prospect at best given the widely attested impossibility of overtly moving material out from non-restrictive relatives (Grosu 1981; Engdahl 1997).

\subsubsection{Undergeneration: Pseudo-DHRCS}

A second empirical issue with EG is that it cannot generate relative clause constructions that lack an internal head like the following:

$$
\begin{aligned}
& \text { Junya-wa [[sakana-ga yake-ta] } \quad \text { sono nioi]-ga kininat-ta. } \\
& \text { Junya-TOP fish-NOM get-broiled-PAST that smell-NOM worry.about-PAST } \\
& \text { 'A fish got broiled, and Junya worried about that smell.' }
\end{aligned}
$$

We call such relative clauses pseudo-DHRCs. Here, there is no relative clause-internal position for nioi (smell), and hence no possibility of constructing a proto relative clause with sono nioi as EH. Since all relative constructions are derived from a proto relative clause for EG, their analysis cannot generate (46).

\subsubsection{Mismatched IH and EH}

A third empirical challenge comes from DHRCs with mismatched $\mathrm{IH}$ and EH. This includes examples where the only thing that could function as an IH is of a different syntactic category from the head as in (47) as well as cases like one version of (8c), repeated below as (48), containing multiple IHs that are distinct from the single EH. 
Junya-wa [[Ayaka-ga tegiwayoku kukkii-o tsukut-ta] sono tegiwayosa]-o Junya-TOP Ayaka-NOM with-finesse cookie-ACC make-PAST that finesse-ACC home-ta.

praise-PAST

'Ayaka made cookies with finesse, and Junya praised that finesse.'

$$
\begin{aligned}
& \text { Junya-wa }[\text { [John-ga san-ko-no nashi-o kat-te Mary-ga ni-ko-no } \\
& \text { Junya-TO John-NOM three-CL-GEN pear-ACC buy-and Mary-NOM two-CL-GEN } \\
& \text { ringo-o kat-ta] sono kudamono]-o tabe-ta. } \\
& \text { apple-ACC buy-PAST that fruit-ACC eat-PAST } \\
& \text { 'John bought three pears and Mary bought two apples and Junya ate that fruit } \\
& \text { (= the } 3 \text { pears and the } 2 \text { apples).' }
\end{aligned}
$$

In (47), tegiwayoku (with finesse) is an adverbial, while tegiwayosa (finesse) is a noun. If the latter is to be derived from the former through copy movement, it will be necessary to copy not the expression as a whole but only its root tegiwayo, adding the nominalizing suffix -sa to the higher copy. For the sake of argument, accept that such a derivation is possible. The next question that arises is which of these expressions gets pronounced. Empirically, it is possible for only the EH nominal to be pronounced, generating the EHRC in (49a). However, pronouncing only the adverbial in (49b), generating an IHRC referring to Ayaka's finesse, is impossible.

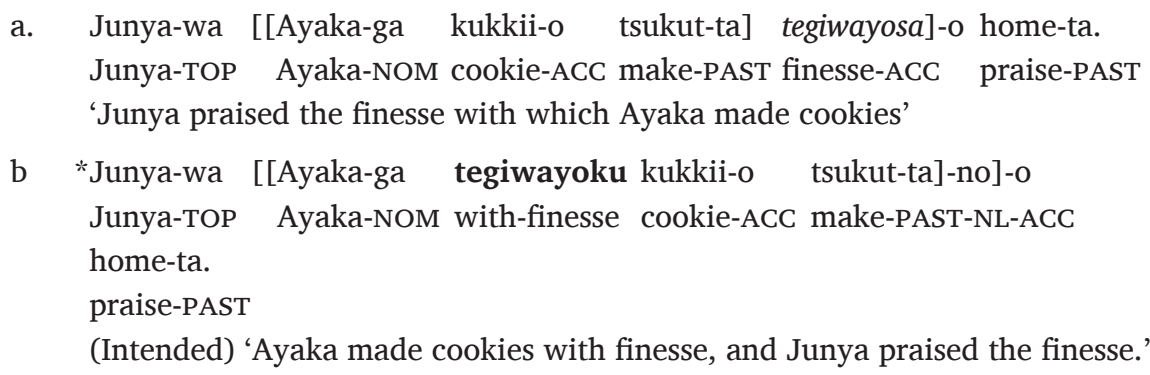

It is unclear how EG can account for these facts in a principled manner. The acceptability of (49a) suggests that it is possible to not pronounce a category-defining morpheme - here the adverbial-forming $k u$ - when its root is not pronounced. If we accept that conclusion, however, then under EG's analysis there is no barrier to not pronouncing the EH of (47) as in (49b).

(48) is even more challenging for EG. Here, the EH sono kudamono (that fruit) is intuitively related to two distinct IHs, san-ko-no nashi (three pears) and ni-ko-no ringo (two apples). However, kudamono is not a copy of either nashi or ringo, and no syntactic operation can merge nashi and ringo into kudamono.

\subsubsection{Predicted uniformity of island effects unattested}

Under EG's analysis, the only movement involved in creating EHRCs, DHRCs and IHRCs occurs during the construction of the proto relative clause. Since all three constructions are derived from the same proto relative clause, island effects are predicted to be uniform across the three constructions. EG claim this prediction is correct. We have seen in section 2.3, however, that it is not. In particular, the unacceptability of $(7 \mathrm{~b}, \mathrm{c})$ and $(8)$ shows that IHRCs are subject to island constraints, while the acceptability of their DHRC counterparts in $(8 \mathrm{a}, \mathrm{b}, \mathrm{d})$ shows that DHRCs are not.

\subsubsection{Unattested KRC effects}

EG claim without demonstration that DHRCs are subject to KRC effects, citing an anonymous reviewer. They account for these alleged effects by stipulating that pronunciation of the lower copy nominal is licensed by satisfaction of the KRC. Both the claim and the analysis are problematic.

That IHRCs are but DHRCs are not subject to KRC effects was shown in section 2.4. In particular, the IHRC examples in (10a,b) showed a contrast in acceptability that is most plausibly explained as deriving from the KRC, with (10a) satisfying the KRC and (10b) not. The parallel DHRC examples in (12a,b), however, did not show a similar contrast. Rather, both were equally acceptable, showing that the KRC plays no role in their acceptability. 


\subsubsection{DHRC syntax}

While superficially similar to IHRCs in having a gapless relative clause, our formal analyses of DHRCs and IHRCs are very different. First, DHRCs have an overt EH, while we analyzed IHRCs as lacking an EH. Second, we analyze DHRCs as grammatizations of E-type anaphora. Like all E-type anaphora, we take the denotation of a DHRC to be recovered from an event rather than from an individual. In contrast to discourse anaphora, the event from which a DHRC recovers its reference lies not in a thematically independent antecedent but rather in its RC argument.

We analyze DHRCs syntactically as gapless relative clause constructions whose EH is a soexpression. ${ }^{23}$ When the $\mathrm{EH}$ is of the form sono $\mathrm{NP}$ it can be understood either as a partitive or as a non-partitive. As a partitive, we analyze the DHRC as a whole as consisting of a DHRC proper having the form [RC so + proN], combined with a genitive case marker and a part-denoting NP, structured as in (50a), where proN is a phonetically null nominal of type et. As a non-partitive, we take so- to combine directly with the overt NP, and for sono NP as a whole to be the EH of the DHRC proper, as in (50b). When the EH consists of a single word such as soitsu, sore, etc., there is no partitive/non-partitive ambiguity, and we analyze the DHRC as having a structure parallel to (50c).
a. $\left[\left[_{\mathrm{DHRC}} \mathrm{RC} s o+\right.\right.$ proN $]-$ no NP $]$
partitive
b. $\quad\left[{ }_{\text {DHRC }}\right.$ RC [sono NP $\left.]\right]$
c. $\quad \mathrm{C}_{\mathrm{DHRC}} \mathrm{RC}$ soitsu $]$
non-partitive
non-partitive

\subsubsection{DHRC semantics}

We analyze the relative clause of a DHRC as a normal clause, without closure (like all integrated embedded clauses). This means it has the semantics of an event quantifier, of type $\langle v t, t\rangle$. The important work of generating a referent from such a clause is done by the semantic head so-, interpreted as follows:

$$
\llbracket s o-\rrbracket=\lambda \mathrm{N}_{e t} \cdot \lambda \mathrm{V}_{\langle v t, t} \cdot \sigma\left(\lambda \mathrm{x}_{e^{*}} \cdot \mathrm{N}(\mathrm{x}) \& \exists \mathrm{e}^{\prime}\left[\mathrm{V}\left(\lambda \mathrm{e}_{v^{*}} \mathrm{e}=\mathrm{e}^{\prime}\right) \& \mathrm{x} \text { is a participant of } \mathrm{e}^{\prime}\right]\right)
$$

So- takes a nominal property $N$ and an event quantifier $V$ and gives back an individual. The individual denoted is the maximal individual $x$ such that $x$ has the property $N$ and $x$ is a participant of the main event of $V$. An individual $x$ is a participant in an event $e$ iff $e$ wouldn't exist without $x \cdot{ }^{24}$ For example, an event of Ayaka making cookies wouldn't exist without Ayaka or without the cookies she makes, and so both Ayaka and the cookies she makes are participants in that event. We illustrate the analysis below:

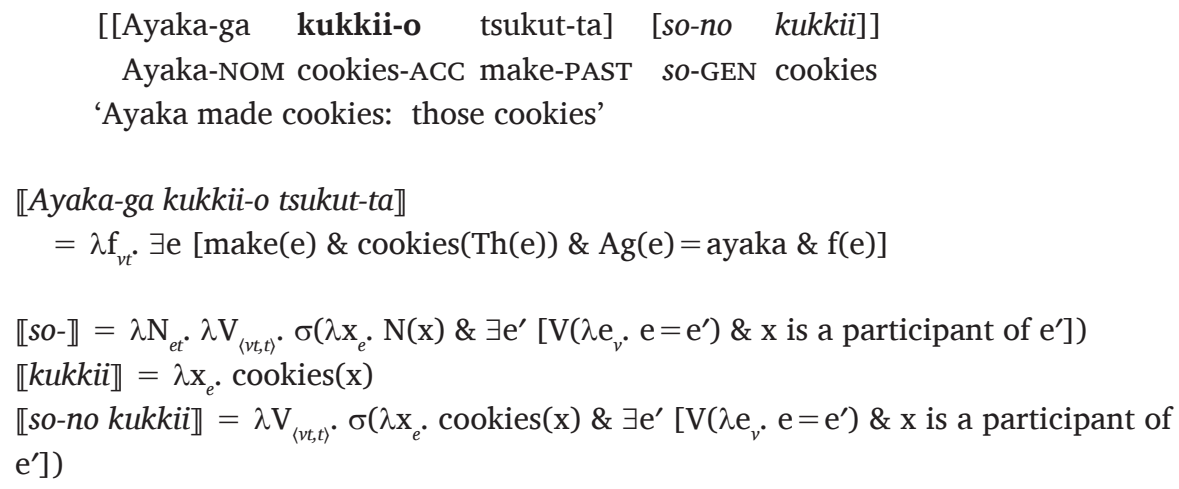

23 These expressions include sore (that), sorera (those), sono NP (that NP), soitsu (that guy), soitsura (those guys), soko (there), sou (that way), sonna (that kind of), socchi (there), and sochira (there).

A reviewer notes that sono NP can alternate with unpronounced anaphors in discourse, and correctly notes that such alternation must be blocked in DHRCs if DHRCs are to be distinguishable from IHRCs. We take the relevant alternation in discourse to be between an event-anaphoric sono NP and an individual-anaphoric pro. In particular, we do not take such anaphora to potentially involve a covert version of sono NP. Since an individual-denoting pro would generate a type clash as the EH for a DHRC, if we accept that sono NP cannot be covert, the absence of a null-headed DHRC follows.

24 We take the participant relation not to require thematic relatedness. A smell, for example, can be a participant in a fish grilling event even if it cannot be thematically related to grill. The analysis thus accommodates pseudoDHRCs as well as normal DHRCs. 
【[ [Ayaka-ga kukkii-o tsukut-ta] [so-no kukkii]] 》

$=\sigma\left(\lambda \mathrm{x}_{e} \cdot \operatorname{cookies}(\mathrm{x}) \& \exists \mathrm{e}^{\prime}\left[\exists \mathrm{e}\left[\right.\right.\right.$ make(e) $\& \operatorname{cookies}(\mathrm{Th}(\mathrm{e})) \& \mathrm{Ag}(\mathrm{e})=$ ayaka $\& \mathrm{e}=\mathrm{e}^{\prime}$

$\& \mathrm{x}$ is a participant of $\left.\left.\left.\mathrm{e}^{\prime}\right]\right]\right)$

$\approx \sigma\left(\lambda \mathrm{x}_{e} \cdot \operatorname{cookies}(\mathrm{x}) \& \exists \mathrm{e}[\mathrm{make}(\mathrm{e}) \& \operatorname{cookies}(\mathrm{Th}(\mathrm{e})) \& \mathrm{Ag}(\mathrm{e})=\right.$ ayaka

$\& \mathrm{x}$ is a participant of $\mathrm{e}]$ )

\subsubsection{Explanations}

Under the proposed analysis of DHRCs, the RC does not introduce an independent illocutionary act, instead serving to restrict the reference of the DHRC as a whole. This renders DHRCs integrated. This integration derives from the semantics of so-, which allows it to take an event quantifier-denoting clause as a semantic argument. Since the otherwise similar $a$ - and ko- do not have interpretations that allow them to do so, they cannot form integrated DHRCs in the same way. ${ }^{25}$

Our analysis predicts that a DHRC cannot have a unique IH that is contained within a nonintegrated clause. The prediction comes from the interaction of the participant relation and integration. For an integrated event quantifier interpretation $E$, the participants of the main event $e$ of $E$ are those individuals that directly participate in $e$, or in event arguments of $E$, or in event arguments of event arguments of $E$, etc. Non-integration breaks this chain of connection. A clause $C$ that is not integrated with $E$ is a clause that is not connected to $E$ via any such chain, blocking participants in events in $\mathrm{C}$ from being participants of $e$. The only exception to this is cases where a participant of an event of $\mathrm{C}$ and a participant of $e$ are independently represented and identified with each other, e.g. via anaphora. In the absence of such an anaphoric connection, the participants of events in $\mathrm{C}$ and the participants in $e$ are non-overlapping. From this fact we get the prediction that for a DHRC with a unique IH, its IH cannot be in a subclause of the DHRC that is not integrated with the main predicate of the relative clause. That this prediction is borne out can be seen by comparing the following examples, where the nonintegrated clause is underlined.

$$
\begin{aligned}
& \text { a. Junya-wa, [[[kinou [e] kukkii-o tsukut-ta] hito] na-n-da kedo, } \\
& \text { Junya-TOP yesterday gap cookies-ACC make-PAST person COP-NL-COP but } \\
& \text { Ayaka-ga kyoo keeki-o tsukut-ta] sono keeki]-o tabe-ta. } \\
& \text { Ayaka-NOM today cake-ACC make-PAST that cake-ACC eat-PAST } \\
& \text { 'Ayaka - that's the person who made cookies yesterday - made a cake today, } \\
& \text { and Junya ate that cake.' } \\
& \text { b. *Junya-wa [[ [lkinou }[e] \text { kukkii-o tsukut-ta }] \text { hito }] \text { na-n-da kedo, } \\
& \text { Junya-TOP yesterday gap cookies-ACC make-PAST person COP-NL-COP but } \\
& \text { Ayaka-ga kyou keeki-o tsukut-ta] sono kukkii]-o tabe-ta. } \\
& \text { Ayaka-NOM today cake-ACC make-PAST that cookies-ACC eat-PAST } \\
& \text { 'Ayaka - that's the person who made cookies yesterday - made a cake today, } \\
& \text { and Junya ate those cookies.' }
\end{aligned}
$$

(53a) shows that there is no problem in principle with constructing a DHRC from an RC that contains a non-restrictive clause. We see in (53b), however, that that non-restrictive clause cannot contain the head of the DHRC. For analyses of DHRCs like that of Kitagawa (2019) that take the $\mathrm{EH}$ to be anaphoric on a referential antecedent, the unacceptability of (53b) is hard to explain.

The insensitivity of DHRCs to islands derives from the fact that identification of the $\mathrm{IH}$ does not involve movement. The IH is identified as the unique individual that satisfies so-'s internal argument and that is a participant of the main event of the DHRC's relative clause. The participant relation is a semantic-pragmatic relation that is potentially non-local.

A word is in order about the nature of the participant relation. In order to account for the acceptability of pseudo-DHRCs like (46), we have to assume that a smell (nioi) is a participant of an event of a fish getting grilled (sakana-ga yake-ta). Clearly there is no logical connection between events of fish getting grilled and their associated smells. It is logically possible to grill a fish without generating any odor whatsoever. However, there is a clear contextually salient connection between the two: in the real world, grilling a fish generates an odor, and would 
arguably not be the same event if it did not do so. This means that the participant relation has to be analyzed as at least potentially involving contextually salient connections between individuals and events rather than logically necessary connections between the two.

The definiteness of DHRCs comes from the $\sigma$ operator contained in the lexical semantics of their semantic head so-. The denotation of a DHRC is the denotation of a logical expression of the form $\sigma(\mathrm{P})$, which by the definition of $\sigma$ gives us the unique maximal individual that $\mathrm{P}$ is true of.

The lack of KRC effects in DHRCs comes from the absence of a KR operator in the semantics of so-. Formally such an operator could be added to so- just as it was included in $O p$, meaning that the absence of KRC effects in DHRCs is not a theoretical necessity any more than their presence is a necessity in IHRCs. The fact that our analysis of DHRCs differs from our analysis of IHRCs in not involving Op makes it unproblematic, however, that the two constructions differ with respect to KRC effects.

The IH of a DHRC can be an identifying expression such as a name or a demonstrative, setting DHRCs apart from IHRCs. The explanation in section 3.1.4 for the impossibility of individualidentifying IHs in IHRCs rests on the assumption that individual-identifying expressions are of type $e$ and cannot be type-shifted, thus having to be entered into an event domain using an identifying thematic role assigner. This assumption that individual-identifying expressions of type $e$ cannot be type-shifted results in a type clash when combining so- in (51) with a name or demonstrative in the $\mathrm{EH}$ position of a DHRC. We overcome this problem by allowing so- to type shift to the following:

$$
\llbracket s o-\rrbracket=\lambda \mathrm{z}_{e} \cdot \lambda \mathrm{V}_{\langle v t, t\rangle} \cdot \sigma\left(\lambda \mathrm{x}_{e} \cdot \mathbf{x}=\mathbf{z} \& \exists \mathrm{e}^{\prime}\left[\mathrm{V}\left(\lambda \mathrm{e}_{v} \cdot \mathrm{e}=\mathrm{e}^{\prime}\right) \& \mathrm{x} \text { is a participant of } \mathrm{e}^{\prime}\right]\right)
$$

Since IHRCs are not semantically headed by so-, this addition has no effect on their interpretation.

We saw in section 3.2.2, in particular in examples (43) and (45), that a DHRC with the quantificational IH hotondo-no kukkii ( = almost all of the cookies) is restricted in its possible interpretation. If we distinguish the domain over which hotondo operates - the 20 cookies Ayaka made - from the witnesses that render the relative clause true - the 18 cookies that Yoko put in the fridge - in those examples, we saw that for a DHRC the denotation can be the witnesses but cannot be all of the cookies in the domain unless they are all witnesses as well. On our analysis, this fact is derived from the interaction of the semantics of hotondo with the participant relation in the semantics of so-.

We analyze hotondo as operating over a contextually identified domain D. For hotondo-no kukkii, we take D to be a plurality of cookies, i.e. a sum of atomic cookies (cf. Link 1983). We analyze hotondo as follows, where $\subseteq$ is the (plural) part-of relation, $D-x$ is the plural individual that results from removing all the atomic individuals in $x$ from $D,|\mathrm{x}|$ is the number of atomic individuals that are part of $\mathrm{x}$, and $m \gg n$ is true iff $m$ is far greater than $n$.

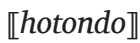

$$
\begin{aligned}
& =\lambda \mathrm{N}_{e t^{*}} \lambda \theta_{\langle e,\langle\langle v t, t),\langle v t, t)\rangle\rangle^{*}} \lambda \mathrm{P}_{\langle\nu t, t\rangle^{*}} \cdot \lambda \mathrm{f}_{v t^{*}} \exists \mathrm{z}[\mathrm{z} \subseteq \mathrm{D} \& \mathrm{~N}(\mathrm{z}) \&|\mathrm{z}| \gg|\mathrm{D}-\mathrm{z}| \& \theta(\mathrm{z})(\mathrm{P})(\mathrm{f})]
\end{aligned}
$$

This produces the following interpretation for the DHRC in (43):

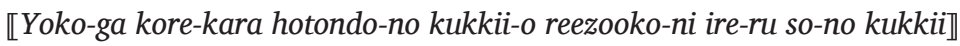

$$
\begin{aligned}
& =\llbracket s o-\rrbracket(\llbracket k u k k i i \rrbracket)(\llbracket Y o k o-g a \text { kore-kara hotondo-no kukkii-o reezooko-ni ire-ru } \rrbracket) \\
& =\left[\lambda \mathrm{N}_{e t} \cdot \lambda \mathrm{V}_{\left\langle v t, t^{\dagger}\right.} \cdot \sigma\left(\lambda \mathrm{x}_{e^{*}} \mathrm{~N}(\mathrm{x}) \& \exists \mathrm{e}^{\prime}\left[\mathrm{V}\left(\lambda \mathrm{e}_{v^{*}} \cdot \mathrm{e}=\mathrm{e}^{\prime}\right) \& \mathrm{x} \text { is a participant of } \mathrm{e}^{\prime}\right]\right)\right] \\
& (\lambda \mathrm{x} . \operatorname{cookies}(\mathrm{x})) \\
& \left(\lambda \mathrm{f}_{v t^{\circ}} \exists \mathrm{z}[\operatorname{cookies(D)} \& \mathrm{z} \sqsubseteq \mathrm{D} \&|\mathrm{z}| \gg|\mathrm{D}-\mathrm{z}| \text { \& } \exists \mathrm{e} \text { [put(e) \& Ag(e)=yoko \& }\right. \\
& \mathrm{Th}(\mathrm{e})=\mathrm{z} \& \operatorname{Goal}(\mathrm{e})=\text { the.fridge } \& \mathrm{f}(\mathrm{e})]]) \\
& =\sigma\left(\lambda \mathrm{x}_{e} \cdot \operatorname{cookies}(\mathrm{x}) \& \exists \mathrm{e}^{\prime}[\exists \mathrm{z}[\operatorname{cookies}(\mathrm{D}) \& \mathrm{z} \sqsubseteq \mathrm{D} \&|\mathrm{z}| \gg|\mathrm{D}-\mathrm{z}| \& \exists \mathrm{e}[\operatorname{put}(\mathrm{e}) \&\right. \\
& \left.\left.\operatorname{Ag}(e)=\text { yoko } \& \operatorname{Th}(e)=z \& \operatorname{Goal}(e)=\text { the.fridge } \& e=e^{\prime}\right]\right] \& x \text { is a participant } \\
& \text { of } \left.\mathrm{e}^{\prime}\right] \text { ) } \\
& =\sigma\left(\lambda \mathrm { x } _ { e ^ { \cdot } } \cdot \operatorname { c o o k i e s } ( \mathrm { x } ) \& \exists \mathrm { e } ^ { \prime } \left[\exists \mathrm { z } \left[\operatorname{cookies}(\mathrm{D}) \& \mathrm{z} \sqsubseteq \mathrm{D} \&|\mathrm{z}| \gg|\mathrm{D}-\mathrm{z}| \& \operatorname{put}\left(\mathrm{e}^{\prime}\right) \&\right.\right.\right. \\
& \left.\left.\left.\operatorname{Ag}\left(\mathrm{e}^{\prime}\right)=\text { yoko } \& \operatorname{Th}\left(\mathrm{e}^{\prime}\right)=\mathrm{z} \& \operatorname{Goal}\left(\mathrm{e}^{\prime}\right)=\text { the.fridge }\right] \& \mathrm{x} \text { is a participant of } \mathrm{e}^{\prime}\right]\right)
\end{aligned}
$$

This denotes the cookies that are participants of some event of Yoko putting cookies into the fridge. The important thing to focus on here is the different roles played by $D$ and $z$ with respect to the putting event $e^{\prime}$. In particular, a witness for $z$ is directly thematically related 
to $e^{\prime}$ in the final line, making that witness a participant of $e^{\prime}$. In contrast, $D$, the domain of cookies, only serves to place restrictions on $z$. It is not thematically related to $e^{\prime}$ either directly or indirectly and does not count as an independent participant of $e^{\prime}$ in any other way. The denotation of the DHRC is then the maximal plurality $x$ of cookies such that for some event $e^{\prime}$ of Yoko putting cookies in the fridge, $x$ is a participant of $e^{\prime}$. For a situation like the one envisioned for (43) in which there is only a single event of Yoko putting cookies in the fridge, this results in the DHRC denoting the witnesses for $z$, not the domain $D$, with respect to that event.

We saw in section 3.2.2 (Mismatched IH and EH) that the EH and the IH of a DHRC can be mismatched. This is expected under our analysis. Consider (48), repeated here. ${ }^{26}$

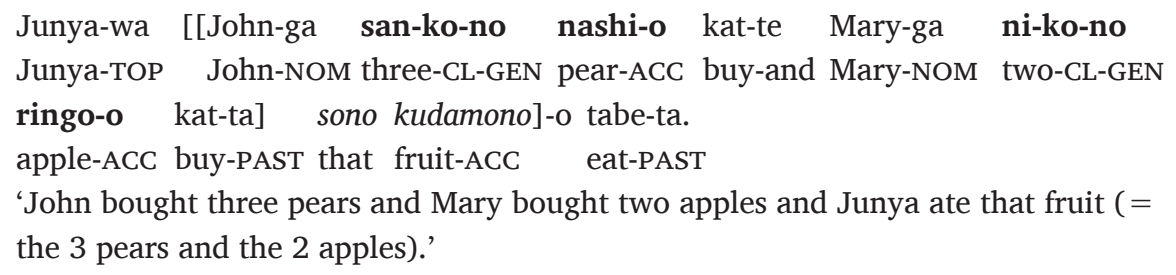

This example has a single EH, sono kudamono (that fruit), but two corresponding IHs, san-ko-no nashi (three pears) and ni-ko-no ringo (two apples). According to the semantics of so-, the DHRC is predicted to refer to the maximal plurality of fruit that counts as a participant in the conjoined buying event, i.e. to the three pears and two apples that John and Mary bought. This is exactly what the DHRC is understood to refer to.

\section{Conclusion}

This paper has offered detailed syntactic and semantic analyses of two of the relative constructions of Japanese, IHRCs and (integrated) DHRCs. Its central goal has been to capture, with minimal appeal to stipulation, ways in which these two constructions differ from each other, from the other relative constructions, and from discourses with an anaphoric dependency. Our approach is critically contrasted with EG, which aimed at a maximal analytical unification of EHRCs, IHRCs and DHRCs, but fails to account for the differences among them.

The analysis of IHRCs builds on Landman (2016), but differs from Landman's analysis in the following respects:

[i] Syntactically, IHRCs are CPs without a null EH.

[ii] Kuroda Relevancy targets only eventualities expressed by hierarchically adjacent constituents: the IHRC itself, and the predicate that selects it.

[iii] The class of islands to which IHRCs are sensitive was descriptively expanded to include the Coordinate Structure Constraint and the Left Branch Condition.

[iv] In keeping with Grosu (2010), Grosu \& Landman (2012), and Landman (2016), the analysis discloses a quantified nominal (the IH), but achieves this effect by means of an independently existing mechanism of thematic role assignment, which replaces the essentially ad hoc 'Choose Role' mechanism and the otherwise unattested empty post-position in these studies.

[v] As in the earlier studies mentioned under [iv] above, island sensitivity is accounted for by the raising of a Null Operator $(O p)$. However, this $O p$ is endowed with a richer lexical entry that enables it to also account for integration, for the unique individual denotation of the IHRC, and for the observed requirement that the KRC only restricts hierarchically adjacent eventualities (see [ii]). Under this analysis, an IHRC CP contributes an individual to the denotation of the sentence as part of the interpretation 
of $\mathrm{Op}$. This CP thus differs non-trivially from the status attributed to it in Hoshi (1995), Shimoyama (1999; 2001), Kim (2007) and Kitagawa (2019), where it was viewed as denoting a proposition, and from the status it had in Grosu (2010), Grosu \& Landman (2012), and Landman (2016), where it was analyzed as a predicate.

[vi] An analysis was given of the inability of names and demonstrative phrases to serve as felicitous IHs.

The analysis of DHRCs differs radically from all analyses of DHRCs and IHRCs we are aware of, including the analysis of IHRCs presented in this paper. The difference between DHRCs and IHRCs is motivated by the fact that DHRCs lack most of the restrictions that distinguish IHRCs from discourses containing anaphoric dependencies. Indeed, the only property we examined that the two constructions share is integration.

In contrast to the view assumed in Grosu \& Hoshi (2019), the CP of a DHRC is not analyzed here as a predicate, but as an event quantifier. Integration is captured through the lexical entry for so- - the semantic head of a DHRC - taking CP as one of its arguments.

It is suggested that DHRCs constitute a grammatization of an E-type anaphoric dependency, differing from the latter in the denotation of the DHRC being recovered not from a thematically unrelated antecedent, but from a participant of the main event of its CP argument.

Finally, the paper extends the empirical domain in need of explanation beyond that found in earlier literature, in noting and illustrating the fact that DHRCs exist in two varieties, integrated and appositive.

\section{Appendix: Change IHRCs}

The analysis presented has not yet been shown to be able to handle either Change IHRCs or IHRCs and DHRCs with multiple IHs. Concerning IHRCs with multiple IHs we have nothing new to add to the analysis of Grosu \& Landman (2012) involving plural thematic roles and plural events. DHRCs with multiple IHs and thus multiple EHs we analyze as involving conjunction of two full DHRCs with ellipsis of the second RC. In contrast to these, Change IHRCs fall out from our analysis without additional stipulation. In this appendix, we first defend our assumption that Change IHRCs exist, and then show how our analysis generates them.

The sentence in (57) has the general form of an IHRC. However, the denotation of the bracketed expression is not that of its putative IH ringo (apple) but rather the juice that resulted from squeezing the apple.

$$
\begin{aligned}
& \text { Bill-wa [[Mary-ga ringo-o shibottekure-ta]-no]-o non-da. } \\
& \text { Bill-ToP Mary-NOM apple-ACC squeeze-PAST-NL-ACC drink-PAST } \\
& \text { 'Mary squeezed apples and Mary drank (the resulting juice).' }
\end{aligned}
$$

This example was introduced into the literature in Hoshi (1995), and such examples came to be called Change IHRCs later (see Tonosaki 1998). In their section 6, Grosu \& Hoshi (2016) argue that unambiguous Change IHRCs can be obtained by felicitously coordinating them with incontrovertible IHRCs, a proposal which relies on the assumption that IHRCs and EHRCs cannot be coordinated. We reproduce in (58)-(59) Grosu \& Hoshi's (55)-(56), which they offered in support of their claims. In both examples, the first conjunct is presumed to be an IHRC; in (58), the second conjunct is an incontrovertible light-headed pseudo-EHRC, with resulting infelicity, and in (59), it is a 'disputed' Change IHRC or a light-headed pseudo-EHRC. The contrast in felicity between (58) and (59) leads Grosu \& Hoshi to the conclusion that the second conjunct in (59) must be a Change IHRC.

$$
\begin{aligned}
& \text { *Bill-wa [[[John-ga wain-o dashitekure-ta]-no] to [[[Mary-ga ringo-o } \\
& \text { Bill-TOP John-NOM wine-ACC serve-PAST-NL and Mary-NOM apple-ACC } \\
& \text { shibottekure-ta] oishisoona]-no]]-o } \quad \text { (san-bai) non-da. } \\
& \text { squeeze-PAST delicious.looking-one-ACC three-CL drink-PAST } \\
& \text { 'John served wine and Mary squeezed apples, and Bill drank } \text { it, three glasses of } \\
& \text { them altogether\} (= the wine and apple juice).' }
\end{aligned}
$$


Bill-wa [[[John-ga wain-o dashitekure-ta]-no] to [[Mary-ga ringo-o

Bill-TOP John-NOM wine-ACC serve-PAST-NL and Mary-NOM apple-ACC

shibottekure-ta]-no]]-o (san-bai) non-da.

squeeze-PAST-NL-ACC three-CL drink-PAST

'John served wine and Mary squeezed apples, and Bill drank \{it, three glasses of them altogether\} (= the wine and apple juice).'

Kitagawa (2019) correctly points out that 'the coordination test does not necessarily tease out the construction type "change IHRC" as an authentic IHRC', in view of the fact that examples like (58) can be substantially improved by semantic-pragmatic manipulation, as in (60) ( = his (16)), where the coordination serves to 'enhance a particular theme', which runs through both conjuncts.

$$
\begin{aligned}
& \text { Bokutachi-wa [[[John-ga wain-o tsuidekure-ta]-no] to [[[Mary-ga } \\
& \text { we-TOP John-NOM wine-ACC pour-PAST-NL and Mary-NOM } \\
& \text { ringo-o shibottekure-ta] oishisoona]-no]]-o non-de yatto kutsuroi-da. } \\
& \text { apple-ACC squeeze-PAST delicious.looking-one-ACC drink finally relax-PAST } \\
& \text { 'John served wine and Mary the very delicious looking stuff that she made by } \\
& \text { squeezing apples, and we relaxed finally.' }
\end{aligned}
$$

We maintain that the RC construction in the second conjunct of (59) is a Change IHRC. However, it is difficult to show this using the examples given, and we accept that Kitagawa's observation calls that assumption into question. We thus propose an independent argument for the existence of Change IHRCs.

It has long been noted that using certain occurrences of no to refer to people is considered degrading toward the person referred to (see, e.g., Kuroda 1976/77; 1992). The occurrence of no in a light-headed EHRC is one of these occurrences, as can be seen in the following example:

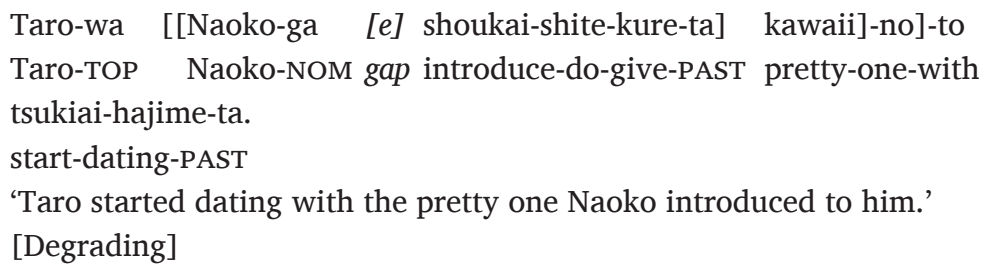

When we look at a light-headed pseudo-EHRC understood to refer to a human as in (62), we find the same phenomenon - it is seen as degrading toward the person referred to.

$$
\begin{aligned}
& \text { [[[Majo-ga omajinai-de shoojo-o henshin-sase-ta] } \\
& \text { good fairy-NOM magic.spells-with girl-ACC transform-cause-PAST } \\
& \text { koounna-no]-no konouenai utsukushisa]-ga oojisama-o torikonishi-ta. }
\end{aligned}
$$$$
\text { fortunate-NL-GEN extraordinary beauty-NOM prince-ACC get-enslaved-PAST }
$$$$
\text { 'The good fairy transformed a girl with magic spells, and her extraordinary }
$$$$
\text { beauty enslaved the prince.' }
$$

[Degrading]

The presence of the adjective koounna (fortunate) before no here makes an IHRC parse impossible, and the only remaining options for parsing the sentence result in an occurrence of no that comes out as degrading the beautiful girl being referred to. When the adjective is removed, however, the degradation disappears as well.

$$
\begin{aligned}
& \text { [[[Majo-ga omajinai-de shoojo-o henshin-sase-ta]-no]-no } \\
& \text { good fairy-NOM magic.spells-with girl-ACC transform-cause-PAST-NL-GEN } \\
& \text { konouenai utsukushisa]-ga oojisama-o torikonishi-ta. } \\
& \text { extraordinary beauty-NOM prince-ACC get-enslaved-PAST } \\
& \text { 'The good fairy transformed a girl with a magic spell, and her extraordinary } \\
& \text { beauty enslaved the prince.' } \\
& \text { [Not degrading] }
\end{aligned}
$$


The non-degrading nature of the reference in (63) suggests that (63) can be understood in a way that (62) cannot. We contend that this extra way is as a Change IHRC. The contrast does not constitute proof of our claim. However, no obvious alternatives present themselves, and as we will see immediately below, an IHRC analysis of (63) is expected to be possible under the analysis of IHRCs in Section 3.1.

The analysis of Section 3.1 generates IHRCs by combining Op with a thematic role assigner in the sister to an event quantifier. In all of the cases examined, the relevant thematic role assigner doubles up on a role that was already assigned. However, this doubling up is not a requirement of the analysis. An IHRC could just as well be formed by adding a thematic role assigner assigning a role that ends up assigned only once. We can see that such a role exists in (63) by considering the following sentence, where the relevant argument is made overt:

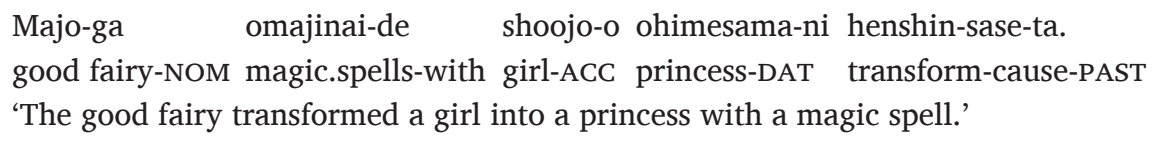

By combining $O p$ with the thematic role assigner that assigns ohimesama (princess) its role in (64), we generate the relevant RC construction in (63) as an IHRC, whose IH is not overtly expressed. Change IHRCs thus do not require any special treatment under the present analysis. They fall out for free as variants of normal IHRCs.

\section{Abbreviations}

$\mathrm{ACC}=$ accusative, $\mathrm{COP}=$ copula, $\mathrm{CL}=$ classifier, $\mathrm{DAT}=$ dative, $\mathrm{GEN}=$ genitive, $\mathrm{NL}=$ nominalizer, $\mathrm{NOM}=$ nominative, $\mathrm{PAST}=$ past tense; PRES $=$ present tense; $\mathrm{Q}=$ question morpheme, TOP $=$ topic

\section{Acknowledgements}

We are deeply grateful to three anonymous reviewers, whose perceptive and detailed comments on two earlier versions of this article have enabled us to produce a substantially improved final version. We also wish to thank Miyuki Yamashina for acting as a sophisticated native consultant for most of the data in this paper, and Aron Hirsch for discussion, in connection with an earlier manuscript on the same general topic, of possible analytical similarities and differences between IHRCs and DHRCs. Last but not least, we wish to thank Johan Rooryck for running the review process with supreme efficiency.

\section{Competing interests}

The authors have no competing interests to declare.

\section{Author affiliations}

Christopher Tancredi

Keio University, JP

Koji Hoshi

Keio University, JP

Alexander Grosu

Tel Aviv University, IL

\section{References}

Bobaljik, Jonathan David. 1995. Morphosyntax: The syntax of verbal inflection. Massachusetts Institute of Technology. (Ph.D. dissertation.)

Champollion, Lucas. 2015. The interaction of compositional semantics and event semantics. Linguistics and Philosophy 38. 31-66. DOI: https://doi.org/10.1007/s10988-014-9162-8

Engdahl, Elisabet. 1977. Relative clause extractions in context. Working Papers in Scandinavian Syntax 60. 51-79. 
Erlewine, Michael Yoshitaka \& Isaac Gould. 2016. Unifying Japanese relative clause: Copy-chains and context-sensitivity. Glossa: A Journal of General Linguistics 1(1). 51. 1-40. DOI: https://doi. org/10.5334/gjgl.174

Grosu, Alexander. 1981. Approaches to island phenomena. North Holland Linguistic Series No. 45. Amsterdam: North Holland Publishing Company.

Grosu, Alexander. 2010. The status of the internally-headed relatives of Japanese/Korean within the typology of definite relatives. Journal of East Asian Linguistics 19. 231-274. DOI: https://doi. org/10.1007/s10831-010-9061-0

Grosu, Alexander \& Koji Hoshi. 2016. Japanese internally headed relatives: Their distinctness from potentially homophonous constructions. Glossa: A Journal of General Linguistics 1(1). 32. 1-31. DOI: https://doi.org/10.5334/gigl.104

Grosu, Alexander \& Koji Hoshi. 2018. On the unified analysis of three types of relative clause construction in Japanese, and on the "salient reading" of the internally headed type. A reply to Erlewine \& Gould (2016). Glossa: A Journal of General Linguistics 3(1). 34. 1-16. DOI: https://doi.org/10.5334/gjgl.577

Grosu, Alexander \& Koji Hoshi. 2019. Japanese internally-headed and doubly-headed relative constructions, and a comparison of two approaches. Glossa: A Journal of General Linguistics 4(1). 128. 1-23. DOI: https://doi.org/10.5334/gigl.1035

Grosu, Alexander \& Fred Landman. 2012. A quantificational disclosure approach to Japanese and Korean internally headed relatives. Journal of East Asian Linguistics 21. 159-196. DOI: https://doi. org/10.1007/s10831-011-9086-\%

Heim, Irene \& Angelika Kratzer. 1998. Semantics in generative grammar. Oxford: Blackwell.

Hoshi, Koji. 1995. Structural and interpretive aspects of head-internal and head-external relative clauses. University of Rochester. (Ph.D. dissertation.)

Josephs, Lewis S. 1976. Complementation. In Masayoshi Shibatani (ed.), Syntax and semantics 5: Japanese generative grammar, 307-369. New York: Academic Press. DOI: https://doi. org/10.1163/9789004368835_009

Kim, Min-Joo. 2007. Formal linking in internally headed relatives. Natural Language Semantics 15. 279315. DOI: https://doi.org/10.1007/s11050-007-9020-0

Kitagawa, Chisato. 2005. Typological variations of head-internal relatives in Japanese. Lingua 115. 12431276. DOI: https://doi.org/10.1016/j.lingua.2004.03.003

Kitagawa, Chisato. 2019. The pro-head analysis of the Japanese internally-headed relative clause. Glossa: A Journal of General Linguistics 4(1). 62. 1-31. DOI: https://doi.org/10.5334/gjgl.857

Kratzer, Angelika. 1996. Severing the external argument from its verb. In Johan Rooryck \& Laurie Zaring (eds.), Phrase structure and the lexicon, 109-137. Dordrecht: Kluwer Academic Publishers. DOI: https://doi.org/10.1007/978-94-015-8617-7_5

Kuno, Susumu. 1973. The structure of the Japanese language. Cambridge, MA: MIT Press.

Kuroda, Shige-Yuki. 1975/76. Pivot independent relativization in Japanese II. In Papers in Japanese Linguistics 3. 59-93.

Kuroda, Shige-Yuki. 1992. Japanese syntax and semantics. Berlin: Springer [Kluwer]. DOI: https://doi. org/10.1007/978-94-011-2789-9

Kuroda, Shige-Yuki. 1999a. Shubu naizai kankeisetsu [Internally headed relative clauses]. In ShigeYuki Kuroda \& Masaru Nakamura (eds.), Kotoba-no kaku-to shuunen [The core and the periphery of language]. 27-103. Tokyo: Kurosio.

Kuroda, Shige-Yuki. 1999b. Notes on so-called head-internal relative clauses in Japanese. In Masatake Muraki \& Enoch Iwamoto (eds.), Linguistics: In search of the human mind: A festschrift for Kazuko Inoue, 414-429. Tokyo: Kaitakusha.

Landman, Fred. 2016. Japanese internally headed relatives: A hybrid analysis with Kuroda functions. Glossa: A Journal of General Linguistics 1(1). 1-35. 36. DOI: https://doi.org/10.5334/gjgl.153

Link, Godehard. 1983. The logical analysis of plurals and mass terms: A lattice-theoretical approach. In Rainer Bäuerle, Urs Egl \& Arnim von Stechow (eds.), Meaning, use and interpretation of language. DeGruyter. 303-329. DOI: https://doi.org/10.1515/9783110852820.302

Makino, Seiichi. 1970. Some aspects of Japanese nominalizations. Tokyo: Tokai Daigaku Press.

Moulton, Keir \& Junko Shimoyama. 2018. On the inverse trace conversion and maximal informativeness analysis of Japanese internally-headed relative clauses: A reply to Erlewine and Gould 2016. Glossa: A Journal of General Linguistics 4(1). 5. 1-27. DOI: https://doi.org/10.5334/gjgl.505

Nakau, Minoru. 1973. Sentential complementation in Japanese. Tokyo: Kaitakusha.

Shimoyama, Junko. 1999. Internally headed relative clauses in Japanese and E-type anaphora. Journal of East Asian Linguistics 8. 147-182. DOI: https://doi.org/10.1023/A:1008338020411

Shimoyama, Junko. 2001. Wh-constructions in Japanese. University of Massachusetts Amherst. (Ph.D. dissertation.)

Stowell, Timothy. 1981. Origins of phrase structure. Massachusetts Institute of Technology. (Ph.D. dissertation.)

Watanabe, Akira. 1992. Subjacency and S-structure movement of wh-in-situ. Journal of East Asian Linguistics 1. 255-291. DOI: https://doi.org/10.1007/BF00130554 
TO CITE THIS ARTICLE: Tancredi, Christopher, Koji Hoshi and Alexander Grosu. 2021. The syntax and semantics of Japanese internally- and doubly-headed relatives. Glossa: a journal of general linguistics 6(1): 93. 1-31. DOI: https://doi. org/10.16995/glossa.5887

Submitted: 23 April 2021 Accepted: 22 June 2021 Published: 19 July 2021

COPYRIGHT:

(c) 2021 The Author(s). This is an open-access article distributed under the terms of the Creative Commons Attribution 4.0 International License (CC-BY 4.0), which permits unrestricted use, distribution, and reproduction in any medium, provided the original author and source are credited. See http:// creativecommons.org/ licenses/by/4.0/.

Glossa: a journal of general linguistics is a peer-reviewed open access journal published by Open Library of Humanities. 